\title{
Patient education for preventing diabetic foot ulceration (Review)
}

\author{
Dorresteijn JAN, Kriegsman DMW, Assendelft WJJ, Valk GD
}

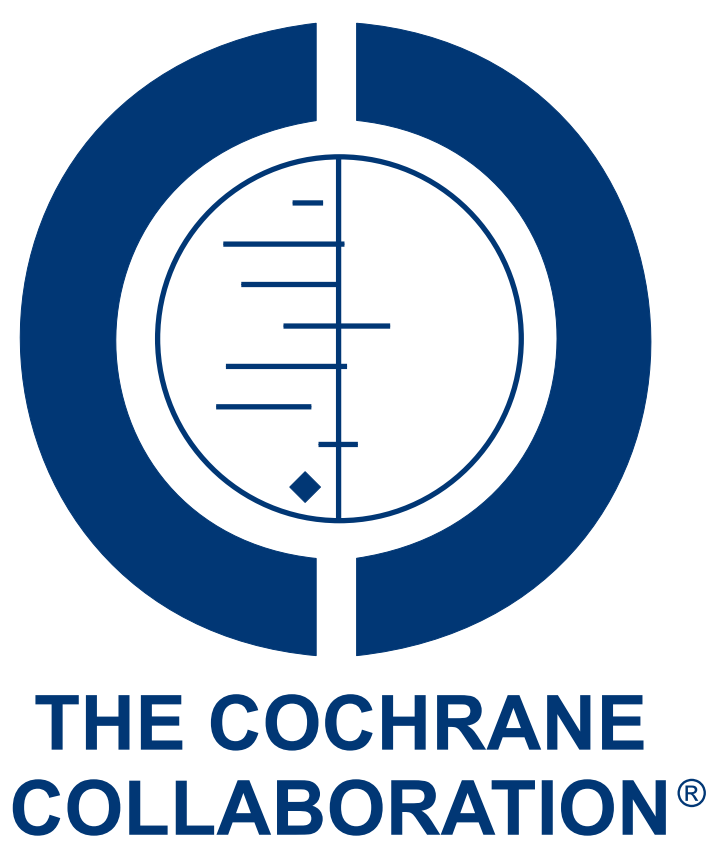

This is a reprint of a Cochrane review, prepared and maintained by The Cochrane Collaboration and published in The Cochrane Library 2010, Issue 5

http://www.thecochranelibrary.com

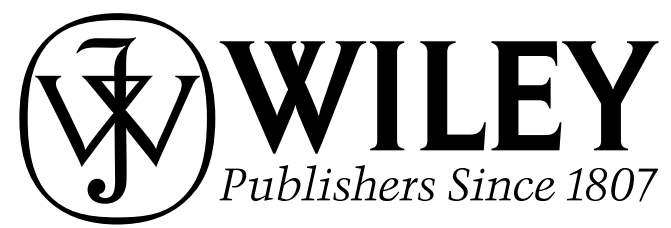

Patient education for preventing diabetic foot ulceration (Review)

Copyright (C) 2010 The Cochrane Collaboration. Published by John Wiley \& Sons, Ltd. 
TABLE OF CONTENTS

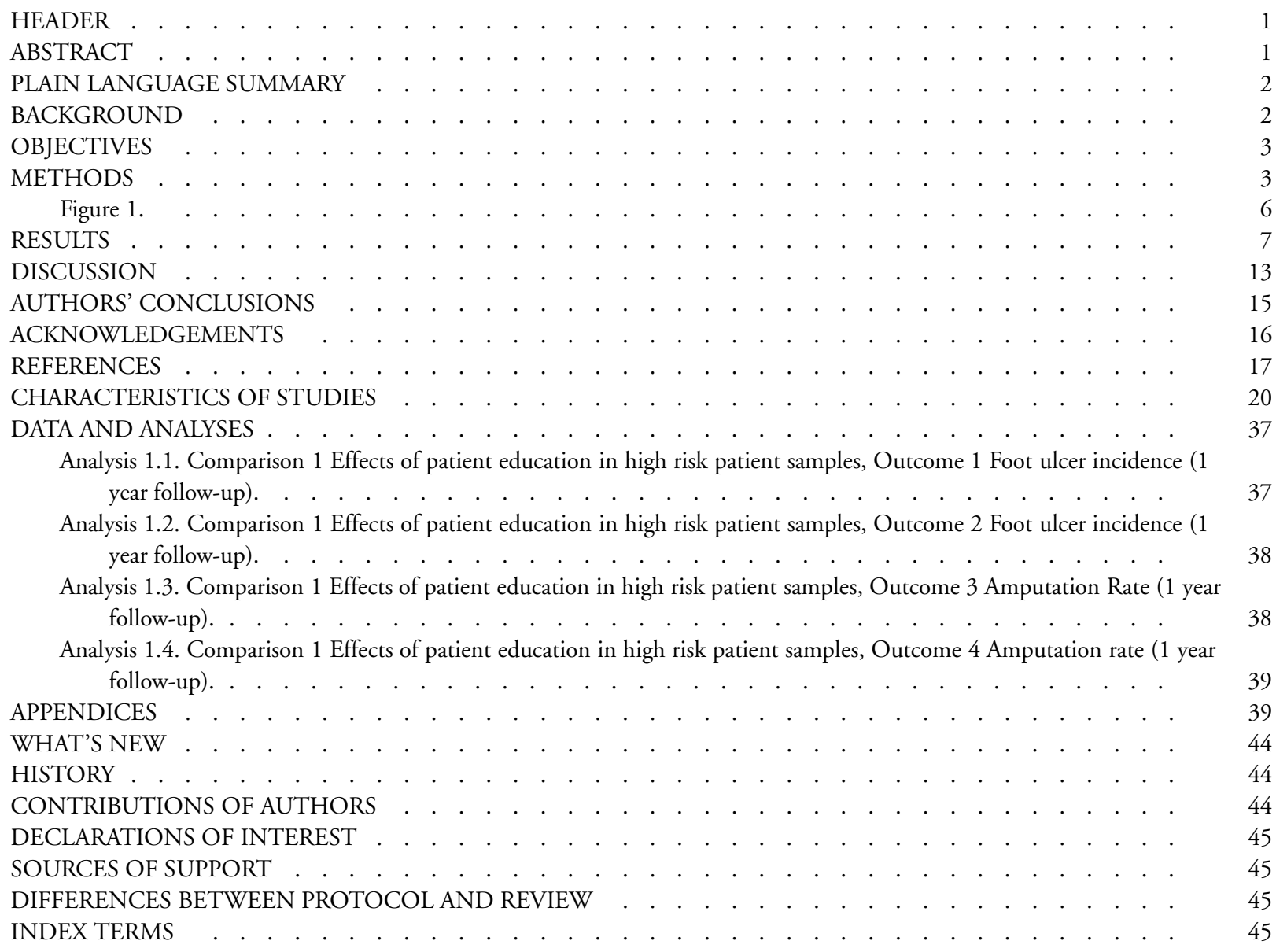




\title{
[Intervention Review]
}

\section{Patient education for preventing diabetic foot ulceration}

\author{
Johannes A N Dorresteijn $^{1}$, Didi M W Kriegsman ${ }^{2}$, Willem JJ Assendelft ${ }^{3}$, Gerlof D Valk ${ }^{1}$ \\ ${ }^{1}$ Department of Internal Medicine, University Medical Center Utrecht, 3508 GA Utrecht, Netherlands. ${ }^{2}$ Zonnehuisgroep Amstelland \\ (KBO), Amstelveen, Netherlands. ${ }^{3}$ Department of Public Health and Primary Care, Leiden University Medical Centre, Leiden, \\ Netherlands \\ Contact address: Gerlof D Valk, Department of Internal Medicine, University Medical Center Utrecht, P.O.Box 85500, 3508 GA \\ Utrecht, Netherlands. g.d.valk@umcutrecht.nl..
}

Editorial group: Cochrane Wounds Group.

Publication status and date: New search for studies and content updated (conclusions changed), published in Issue 5, 2010.

Review content assessed as up-to-date: 28 March 2010.

Citation: Dorresteijn JAN, Kriegsman DMW, Assendelft WJJ, Valk GD. Patient education for preventing diabetic foot ulceration. Cochrane Database of Systematic Reviews 2010, Issue 5. Art. No.: CD001488. DOI: 10.1002/14651858.CD001488.pub3.

Copyright (C) 2010 The Cochrane Collaboration. Published by John Wiley \& Sons, Ltd.

\section{A B S T R A C T}

\section{Background}

Ulceration of the feet, which can result in loss of limbs and even death, is one of the major health problems for people with diabetes mellitus.

\section{Objectives}

To assess the effects of patient education on the prevention of foot ulcers in patients with diabetes mellitus.

\section{Search strategy}

Eligible studies were identified by searching the Cochrane Wounds Group Specialised Register (22 December 2009), the Cochrane Central Register of Controlled Trials (Cochrane Library 2009 Issue 4 ), Ovid MEDLINE (1950 to November Week 3 2009), Ovid MEDLINE In-Process \& Other Non-Indexed Citations (Searched 22/12/09), Ovid EMBASE (1980 to 2009 Week 51) and EBSCO CINAHL (1982 to December 22 2009).

\section{Selection criteria}

Prospective randomised controlled trials (RCTs) which evaluated educational programmes for preventing foot ulcers in people with diabetes mellitus. There was no restriction on language of the publications.

\section{Data collection and analysis}

Two review authors independently undertook data extraction and assessment of risk of bias. Primary end-points were foot ulceration or ulcer recurrence and amputation.

\section{Main results}

Eleven RCTs were included. Three studies described the effect of foot care education as part of general diabetes education compared with usual care. Two studies examined the effect of foot care education tailored to educational needs compared with no intervention. Finally, six studies described the effect of intensive compared with brief educational interventions. Pooling of outcome data was precluded by marked, mainly clinical, heterogeneity. Four RCTs assessed the effect of patient education on primary end-points: foot ulceration and amputations. One of these studies reported a statistically significant benefit of one hour group education after one year of follow-up in people with diabetes who were at high risk for foot ulceration; RR amputation 0.33 (95\% CI 0.15 to 0.76 ); RR ulceration 0.31 ( $95 \%$ 
CI 0.14 to 0.66 ), however this study was at high risk of bias and may have overestimated the effect due to a unit of analysis error. One similar, but methodologically superior study did not confirm this finding; RR amputation 0.98 (95\% CI 0.41 to 2.34 ); RR ulceration 1.00 (95\% CI 0.70 to 1.44). The other two studies did not detect any effect of education on ulcer incidence or amputation but were underpowered. Patients' foot care knowledge was improved in the short term in five of eight RCTs in which this outcome was assessed, as was patients' self reported self care behaviour in the short term in seven of nine RCTs. The effects on callus, nail problems and fungal infections were described in five of the included studies, of which only two reported temporary improvements after an educational intervention.

Only one of the included RCTs was considered to be at low risk of bias.

\section{Authors' conclusions}

Most of the RCTs included in this review are at high or unclear risk of bias. In some trials, foot care knowledge and self reported patient behaviour seem to be positively influenced by education in the short term. This, however, must be viewed with caution. The ultimate goal of educational interventions is preventing foot ulceration and amputation but only four RCTs reported these outcomes and only two reported sufficient data to examine this. Based on these two studies, we conclude that there is insufficient robust evidence that limited patient education alone is effective in achieving clinically relevant reductions in ulcer and amputation incidence.

Future research should focus on evaluating the effect of more comprehensive and/or intensive prevention strategies which may also include patient education (complex interventions).

\section{PLAIN LANGUAGESUMMARY}

\section{Educating people with diabetes about foot care to help reduce foot ulcers and amputations}

Foot ulcers (open sores) are common in people with diabetes, especially those with problems in the nerves (peripheral neuropathy) and/or the blood supply to their legs (peripheral vascular disease). People with ulcers due to diabetes sometimes need an amputation (surgical removal of part of the limb). Foot ulcers not only lead to physical disability and loss of quality of life but also to economic burden (health care costs, industrial disability). The aim is therefore to prevent foot ulcers occurring. This review of high level studies found that educating people with diabetes about the need to look after their feet seems to improve people's foot care knowledge and behaviour in the short term. There is insufficient evidence that education alone, without any additional preventive measures, will effectively reduce the occurrence of ulcers and amputations.

\section{B A C K G R O U N D}

Ulceration of the foot is one of the major health problems for people with diabetes mellitus. It is estimated to affect $15 \%$ to $25 \%$ of people with diabetes at some time in their lives (Singh 2005). Foot ulceration can result in marked physical disability and reduction of quality of life ( Nabuurs-Franssen 2005; Vileikyte 2001), not to mention limb loss and even death (Robbins 2008). Diabetic foot ulcers precede $25 \%$ to $90 \%$ of all amputations ( Global Lower Extremity Amputation Study Group 2000; Pecoraro 1990). The risk of a lower extremity amputation in people with diabetes is therefore much higher than in people without diabetes (Canavan 2008; Icks 2009).

Several factors are involved in the development of foot ulcers, including peripheral neuropathy, peripheral vascular disease (PVD), limited joint mobility and repeated trauma from abnormal load distribution on the foot (Dinh 2005; Edmonds 2006). The underlying causes of foot ulcers are usually irreversible and chronically progressive. Therefore, $70 \%$ of healed foot ulcers recur within five years (Apelqvist 1993). Moreover, treatment itself is very challenging and often needs to be long lasting. It requires not only expert interference, orthopaedic appliances and antimicrobial drugs but also costly topical dressings and inpatient care (Boulton 2004; Cavanagh 2005; Edmonds 2006; Jeffcoate 2003; Singh 2005). Not surprisingly, this leads to substantial economic burden. Healing of a single ulcer costs approximately $\$ 17,500$ (1998 US Dollars) (Ragnarson Tennvall 2004). In cases where lower extremity amputation is required, health care is even more expensive: $\$ 30,000$ to 33,500 (Ragnarson Tennvall 2004). These costs do 
not even represent the total economic burden, since costs related to loss of productivity, preventive efforts, rehabilitation and home care should also be considered. When all this is taken into account, 7 to $20 \%$ of total expenditure on diabetes in North America and Europe might be attributable to diabetic foot ulceration (Boulton 2005).

In 1989 one of the main five-year targets of the European Declaration of St. Vincent was to reduce amputations caused by diabetes mellitus by 50\% (St Vincent Declaration 1989). In order to reach these goals, international guidelines underline the need to reduce the incidence of foot ulceration by preventative efforts. This not only includes optimising metabolic control and identification and screening of people at high risk for diabetic foot ulceration, but also patient education in order to promote foot self-examination and foot-care knowledge (American Diabetes Association 2007; Frykberg 2006; IDF clinical guidelines task force 2005).

Recent population-based research suggests that nowadays a meaningful reduction in the incidence of amputations caused by diabetes mellitus has already been achieved. Before the European Assembly in St. Vincent, the relative risk of a lower extremity amputation was still 15 times higher in people with diabetes mellitus than in people without diabetes mellitus (Most 1983). At present, this relative risk has dropped to 8.8 (7.3 to 10.7) in men and 5.7 (4.3 to 7.6 ) in women in one study (Icks 2009) and to 7.7 (5.0 to 12.9) in another (Canavan 2008).

However, it cannot be inferred from these figures that current preventive efforts are effective, since the reduction in amputation incidence may also have resulted from improvements in ulcer treatment. In this review of randomised controlled trials we, therefore, evaluate the effect of education of people with diabetes aiming to promote foot self-care and to prevent the occurrence of foot lesions. Although this type of prevention is nowadays widely advocated and implemented in standard practice, the evidence for the effectiveness is still scarce. Several review articles on the diabetic foot, which include education among the prevention strategies discussed, have been published (Armstrong 1998; Assal 1985; Bild 1989; Boulton 1995; Bowering 2001; Edmonds 1996; Larsson 1995; Levin 1995; Majid 2000; Mason 1999; Mayfield 1998; Rith-Najarian 2000; Singh 2005; Wu 2007). However, only three of these reviews were systematic (Majid 2000; Mason 1999; Singh 2005) and most of these reviews dealt primarily with uncontrolled studies. Furthermore, only two of these reviews assessed the methodological quality of the included studies (Majid 2000; Mason 1999). The overall conclusion of these review articles was that education is effective for the prevention of diabetic foot ulceration, but consequently this conclusion must be treated with care; especially since previous systematic reviews of patient education for adults with, for example, asthma and neck pain, have suggested that health outcomes were unlikely to be improved by limited patient education (Gibson 2002; Haines 2009).
Thus, after reviewing the available evidence, we decided to perform a systematic review of the effectiveness of (components of) education programmes targeted at people with diabetes with the aim of preventing foot ulceration.

\section{O B J E C T I VES}

To determine the effects of educational programmes for people with diabetes mellitus, aimed at preventing foot ulceration.

\section{MET HO D S}

\section{Criteria for considering studies for this review}

\section{Types of studies}

Prospective randomised controlled trials (RCTs) evaluating educational programmes for the prevention of foot ulcers in people with diabetes mellitus. We excluded studies that were solely aimed at optimising blood glucose concentration. An explicit focus on foot care was required.

\section{Types of participants}

Studies involving people aged 18 years or older with Type 1 or Type 2 diabetes mellitus in any health care setting.

\section{Types of interventions}

Studies of educational programmes (or programmes which include education) aiming to reduce the incidence of foot ulceration in people with diabetes mellitus.

Studies where foot care education was part of a larger educational programme (for example, on diabetes in general) were eligible, but education on foot care had to contrast with the control intervention. The foot care education could also be part of a more comprehensive diabetic foot programme, but in these cases patient education on foot care had to be the main contrast with the control intervention. All types of control intervention were considered for inclusion in the review.

\section{Types of outcome measures}

\section{Primary outcomes}

- Foot ulceration or ulcer recurrence.

- Amputation. 


\section{Secondary outcomes}

Disease-oriented outcomes:

- callus development;

- resolution of callus;

- fungal infection;

- number and duration of hospital admissions for diabetic foot problems.

Process outcomes:

- foot care knowledge scores;

- patients' behaviour assessment scores.

Trials were included if secondary outcomes only were reported.

\section{Search methods for identification of studies}

\section{Electronic searches}

For search methods used in the first update of this review are shown in Appendix 1

For this second update the search string was modified from the original version and run in the following electronic databases over all years:

Cochrane Wounds Group Specialised Register (Searched 22/12/ 09)

The Cochrane Central Register of Controlled Trials (CENTRAL)

- The Cochrane Library 2009 Issue 4

Ovid MEDLINE - 1950 to November Week 32009

Ovid MEDLINE - In-Process \& Other Non-Indexed Citations

(Searched 22/12/09)

Ovid EMBASE - 1980 to 2009 Week 51

EBSCO CINAHL - 1982 to December 222009

The following search strategy was used:

\#1 MeSH descriptor Education explode all trees

\#2 patient NEAR/3 education*

\#3 diabetes NEAR/3 education*

\#4 patient NEAR/3 information

\#5 education* NEAR/2 program*

\#6 (foot NEXT care) or footcare

\#7 leaflet* or booklet* or pamphlet* or "poster" or "posters"

\#8 (written or printed or oral) NEAR/3 information

\#9 academic NEXT detailing

\#10 training NEXT program*

$\# 11$ algorithm* or (decision NEXT tree*)

\#12 \#1 OR \#2 OR \#3 OR \#4 OR \#5 OR \#6 OR \#7 OR \#8 OR

\#9 OR \#10 OR \#11)

\#13 MeSH descriptor Foot Ulcer explode all trees

\#14 MeSH descriptor Diabetic Foot explode all trees

\#15 diabet* NEAR/3 ulcer*

\#16 diabet* NEAR/3 (foot or feet)

\#17 diabet* NEAR/3 infection*
\#18 diabet* NEAR/3 wound*

\#19 (\#13 OR \#14 OR \#15 OR \#16 OR \#17 OR \#18)

\#20 (\#12 AND \#19)

The search strategies for Ovid MEDLINE, Ovid EMBASE and EBSCO CINAHL can be found in Appendix 2, Appendix 3 and Appendix 4 respectively. The Ovid MEDLINE search was combined with the Cochrane Highly Sensitive Search Strategy for identifying randomised trials in MEDLINE: sensitivity- and precision-maximizing version (2008 revision); Ovid format (Lefebvre 2008). The EMBASE and CINAHL searches were combined with the trial filters developed by the Scottish Intercollegiate Guidelines Network (SIGN) (SIGN 2009). No date or language restrictions were applied.

\section{Searching other resources}

The bibliographies of all retrieved and relevant publications identified by these strategies and the list of articles that cited previous versions of this review were searched for further studies.

\section{Data collection and analysis}

\section{Selection of studies}

Full copies of potentially eligible studies were obtained and two review authors (GV and DK or GV and JD), acting independently, decided on inclusion or exclusion. In case of disagreement, consensus was reached by discussion between three review authors (GV, DK and JD).

\section{Data extraction and management}

We extracted details of eligible studies and summarised them using a data extraction sheet. We recorded the content of the educational package, plus the content of the total programme, if education was merely one component. Data from multiple reports of individual studies were extracted and the primary reference identified (Borges 2004; Rönnemaa 1997). We recorded all outcomes if different but relevant outcomes were available from different publications of the same RCT. Data regarding the interventions studied, type of outcome measures, duration of follow up, loss to follow up, and outcomes were extracted by two review authors (GV and DK or GV and JD) independently. In case of disagreement, consensus was reached by discussion between three review authors (GV, DK and JD).

\section{Assessment of risk of bias in included studies}

We assigned two review authors (JD and DK or GV) to independently assess each study using the Cochrane Collaboration tool for assessing risk of bias (Higgins 2008). This tool addresses six specific 
domains, namely: sequence generation, allocation concealment, blinding, incomplete outcome data, selective outcome reporting and other issues (e.g. extreme baseline imbalance) (see Appendix 5 for details of criteria on which the judgement was based). Because blinding of patients and health care providers does not appear to be feasible considering the nature of the interventions studied, judgement was solely based on the information provided about blinding of outcome assessors. Blinding and completeness of outcome data were assessed for each outcome separately. Any disagreements were discussed in a consensus meeting. We completed a risk of bias table for each eligible study (see Characteristics of included studies).

We assessed risk of bias using a 'risk of bias summary figure' (see Figure 1), which presents all of the judgements in a cross-tabulation of study by entry. This display of internal validity may guide the weight the reader may give to the results of the particular studies. 
Figure I. Methodological quality summary: review authors' judgements about each methodological quality item for each included study.

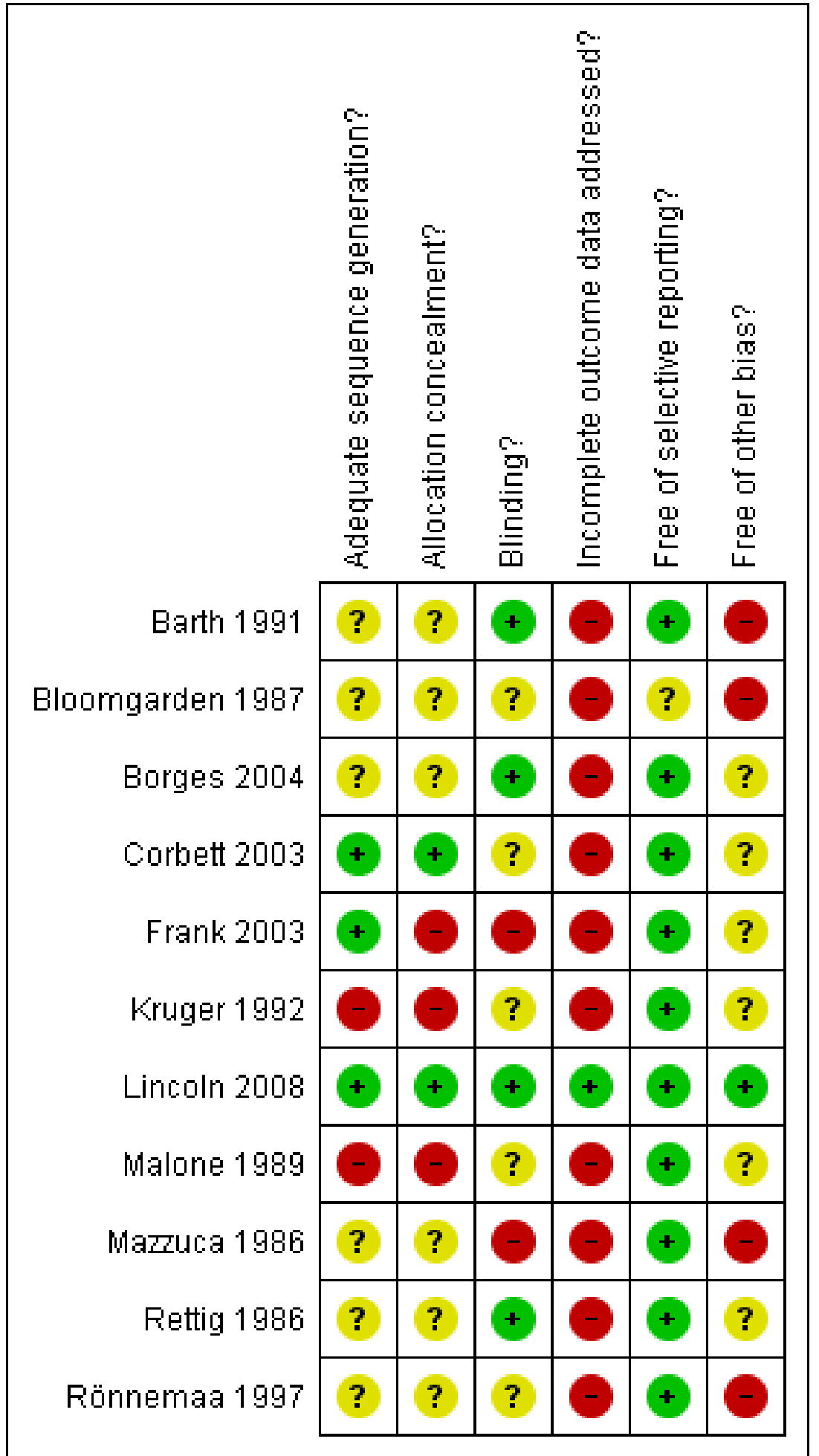

Patient education for preventing diabetic foot ulceration (Review)

Copyright (C) 2010 The Cochrane Collaboration. Published by John Wiley \& Sons, Ltd. 


\section{Measures of treatment effect}

We reported separately for each study. Depending on the available data we aimed to present the results for binary outcomes (e.g. ulceration or amputation) as risk ratios (RR) with corresponding 95\% confidence intervals (CI) and the results for continuous data (e.g. callus diameter) as mean differences with corresponding $95 \%$ confidence intervals.

\section{Dealing with missing data}

If data were missing from reports, we then attempted to contact the study authors. We were successful in contacting the authors of Corbett 2003; Rönnemaa 1997 and Mazzuca 1986, and additional data on effect sizes were obtained.

\section{Data synthesis}

Because substantial statistical and methodological heterogeneity between studies was observed, all results were presented in a qualitative summary (Reed 2005).

\section{Subgroup analysis and investigation of heterogeneity}

Possible sources of variation among studies which would require pre-planned stratified analysis were:

1. character of patient groups (e.g. patients at high risk for foot ulceration compared with patients at low risk; patients with a history of foot ulceration compared with patients without etc.);

2. health care setting;

3. quality of studies;

4. outcome measures used;

5. type of intervention (e.g. brief compared with intensive programmes; education tailored to the individual needs compared with standardised education programmes);

6. nature of contrast (e.g. intervention compared with control intervention; patient education plus co-intervention A compared with intervention A alone; intervention compared with no intervention).

\section{RES U L T S}

\section{Description of studies}

See: Characteristics of included studies; Characteristics of excluded studies.

\section{Results of the search}

For this second update three RCTs were identified and included in the review (Borges 2004; Frank 2003; Lincoln 2008). Further publications were identified for the trial conducted by Rönnemaa 1997 and the primary reference was changed from the previous review (previously identified as Hämäläinen 1998). We have excluded one study in which the intervention consisted of multiple combined strategies for the prevention of diabetic foot ulceration, where patient education was not the main comparator with the control intervention. This study had been included in the previous version of this review (Litzelman 1993). We have developed and published a further Cochrane review which provides a more comprehensive overview of the effects of such integrated prevention strategies (complex interventions)(Dorresteijn 2010). One study has been added to the Characteristics of excluded studies (Schiel 2004).

\section{Included studies}

Eleven RCTs are included in this review and are described in the Characteristics of included studies and summarised below.

\section{Health care settings}

Three RCTs were performed in a community-based care setting (Corbett 2003; Rettig 1986; Rönnemaa 1997): patients were recruited from a home care organisation register (Corbett 2003), hospital records (Rettig 1986) or the national drug imbursement register (Rönnemaa 1997). The care settings of three studies were classified as primary care (Bloomgarden 1987; Frank 2003; Mazzuca 1986): one was performed in a diabetes outpatient clinic in the USA (Bloomgarden 1987), one in a country hospital's outpatient clinic in the USA (Frank 2003) and one in an academic general medicine outpatient clinic in the USA. Four studies were performed in a secondary care setting: one in an outpatient clinic in Australia (Barth 1991), two in secondary outpatient care in the USA (Kruger 1992; Malone 1989) and one in secondary outpatient care in the UK (Lincoln 2008). Finally, one study setting could not be categorised with any of the above, because it was performed in the emergency departments of two community hospitals in the USA (Borges 2004).

\section{Participants' risk of foot ulceration}

In three of the eleven included RCTs, patients were at high risk of foot ulceration (Corbett 2003; Lincoln 2008; Malone 1989). In Malone 1989 all patients were referred to podiatry or vascular surgery prior to study entry and had either foot infection, ulceration or prior amputation. In Lincoln 2008 all participants had 
newly healed diabetic foot ulcers. In Corbett 2003 patients were excluded if they had a history of foot amputation, but it follows from the presence of important risk factors at baseline that the studied population was at high risk for foot ulceration: loss of protective sensation was present in 70\%, impaired lower extremity circulation in $67 \%$ and foot deformity in $50 \%$. In four RCTs patients were at low or medium risk of foot ulceration (Barth 1991; Bloomgarden 1987; Frank 2003; Rönnemaa 1997). In Rönnemaa 1997 patients were even excluded if they had any need for podiatry. Finally in four RCTs, the level of risk for ulceration or amputation could not be determined (Borges 2004; Kruger 1992; Mazzuca 1986; Rettig 1986).

\section{Interventions}

Three RCTs compared the effectiveness of a patient education programme on diabetes in general (which included a component of foot care education) compared with usual care (Bloomgarden 1987; Mazzuca 1986; Rettig 1986). In one of these studies, the content of the educational programme was preset and consisted of nine group patient education sessions, one of which was about foot care and skin hygiene (Bloomgarden 1987). In the other two studies, the content of the educational programme was tailored to patients' individual needs (Mazzuca 1986; Rettig 1986). In Mazzuca 1986 those educational needs were identified using a set of safety-level objectives selected by a multidisciplinary group of health care professionals. These objectives covered seven areas of patient education, of which foot care was one. In the other study areas of diabetes self-management, patients most in need of improvement were determined using an assessment instrument (100 short answer and yes-no questions, brief patient demonstrations of urine testing and insulin injection techniques) (Rettig 1986). In both studies, participants received a variable number of educational sessions.

In addition to Mazzuca 1986 and Rettig 1986, there were two more RCTs which adopted the concept of education tailored to patients' individual needs, but in these studies the educational interventions were only directed at improving foot care (Corbett 2003; Borges 2004) and they were less intensive than in Mazzuca 1986 and Rettig 1986. In Corbett 2003 a single 10 to 20 minute educational session, combined with written instructions, was compared with no intervention, and in Borges 2004 a 15 minute educational session after a risk assessment for foot ulceration was compared with risk assessment alone and with no intervention at all.

In the remaining six RCTs, an intensive foot care education programme was compared with a less proactive intervention (Barth 1991; Frank 2003; Kruger 1992; Lincoln 2008; Malone 1989; Rönnemaa 1997). This, however, does not mean that the interventions in these studies were all similar. In two studies the intervention was only a single hour of patient education, reinforced by hand-outs (Lincoln 2008; Malone 1989). In Malone 1989, this was compared with routine patient education, and in Lincoln
2008 with written instructions only. In Rönnemaa 1997, patients in the intervention group also received 45 minutes of foot care education, but this was combined with a variable number of follow-up visits at a podiatry clinic. The control intervention consisted of written instructions on foot care only. In the other studies, the educational interventions were more comprehensive and/ or more intensive. In Frank 2003, for example, the intervention comprised viewing a videotape about proper foot care, a 30 to 40 minute individualised educational session, a foot ulceration risk assessment, handouts, a foot care checklist, a bag of foot care supplies and weekly reminder telephone calls. Control group patients received a foot ulceration risk assessment only. In two other studies a basic educational programme on diabetes in general was provided to all study participants and supplemented by specific foot care education in the intervention group (Barth 1991; Kruger 1992). In Barth 1991, the general diabetes education consisted of 14 hours of group education and included an hour lecture on foot care. In addition to that, the intervention group followed nine hours of group education about the diabetic foot (Barth 1991). In Kruger 1992, the general diabetes education consisted of a one week course, which included viewing an instructional videotape on foot care. In the intervention group this was supplemented with a 'hands-on' foot care approach, a patient education kit and daily foot care sheets (Kruger 1992).

\section{Duration of follow-up}

The median time to follow-up was six months (Barth 1991; Kruger 1992; Rettig 1986), ranging from only four weeks (Borges 2004; Frank 2003) to seven years (Rönnemaa 1997).

\section{Risk of bias in included studies}

The risk of bias of most included studies was high, except for one RCT (Lincoln 2008). Details are presented in a risk of bias table for each eligible study (see Characteristics of included studies) and in a 'risk of bias summary figure' (see Figure 1), which presents all of the judgements in a cross-tabulation of study by entry. Judgements on the six items were made by two review authors independently for each of the 11 studies. There was initial disagreement on six items (percentage of agreement 91\%). All disagreements were resolved by discussion without needing to consult the third review author. True randomisation with allocation concealment was evident in only two of the included RCTs (Corbett 2003; Lincoln 2008). Four RCTs (Barth 1991; Borges 2004; Lincoln 2008; Rettig 1986) described blinded outcome assessment. The withdrawal/drop-out rate was unacceptable in five RCTs (Borges 2004; Corbett 2003; Kruger 1992; Mazzuca 1986; Rettig 1986). In only one of the RCTs an intention-to-treat analysis was performed for primary outcomes (Lincoln 2008). Co-interventions were avoided or similar in two studies (Borges 2004; Lincoln 2008). The adherence to the interventions reached an acceptable level in four RCTs (Borges 
2004; Corbett 2003; Frank 2003; Lincoln 2008). The most important baseline prognostic indicators were clearly incomparable in two RCTs (Barth 1991; Bloomgarden 1987), sufficiently similar in two others (Frank 2003; Lincoln 2008) and inadequately described in the remaining RCTs.

The eligibility criteria with regard to risk for foot ulceration were sufficiently described in only five RCTs (Borges 2004; Corbett 2003; Frank 2003; Lincoln 2008; Malone 1989).

\section{Effects of interventions}

Additional data are presented in Table 1. Results of studies are summarised below in a study-by-study qualitative synthesis.

Table 1. Results from trials

\begin{tabular}{|c|c|c|}
\hline Study ID & Primary outcomes & Secondary outcomes \\
\hline Barth 1991 & No primary outcomes reported & $\begin{array}{l}\text { Foot problems requiring treatment: } \\
\text { Significant reduction in I after } 1 \text { month }(\mathrm{p}<0.001) \text {, } \\
\text { maintained until final follow-up at six months. } \\
\text { Reduction was significantly smaller in } \mathrm{C} \text { than in I af- } \\
\text { ter } 1 \text { month }(\mathrm{p}<0.006) \text {, but not after six months ( } \mathrm{p}= \\
0.216 \text { ). } \\
\text { Foot care knowledge: } \\
\text { Significant increase in both groups at one month ( } \\
\mathrm{p}<0.001) \text {, but more in I than in } \mathrm{C}(\mathrm{p}<0.001) \text {. Changes } \\
\text { were maintained until final follow-up at six months. } \\
\text { Foot care routine compliance: } \\
\text { Significant increase in I after one month ( } \mathrm{p}<0.001) \text {, } \\
\text { maintained until final follow-up. } \\
\text { Increase was significantly greater in I than in } \mathrm{C} \text { after } \\
\text { one month ( } \mathrm{p}=0.012 \text { ). }\end{array}$ \\
\hline $\begin{array}{l}\text { Bloomgarden } \\
1987\end{array}$ & $\begin{array}{l}\text { Ulcer or amputation: } \\
\text { Patients with no foot lesions at baseline: } \\
\text { I: } 2 / 83 \text { vs C: } 2 / 63 \text {. } \\
\text { Patients with callus, nail dystrophy or fungal infection } \\
\text { at baseline: I: } 2 / 37 \text { vs C: } 3 / 63 \text {. } \\
\text { Patients with an ulcer or amputation at baseline: I: } 6 / \\
7 \text { vs C: } 11 / 13 \text {. }\end{array}$ & $\begin{array}{l}\text { Callus, nail dystrophy and fungal infection: } \\
\text { Patients with no foot lesions at baseline: I: } 31 / 83 \text { vs } \\
\text { C: } 28 / 63 \text { (ns). } \\
\text { Patients with callus, nail dystrophy or fungal infection } \\
\text { at baseline: I: } 24 / 37 \text { vs C: } 46 / 63 \text { (ns). } \\
\text { Patients with an ulcer or amputation at baseline: I: } 1 \text { / } \\
7 \text { vs C: } 1 / 13 \text { (ns). } \\
\text { Behaviour assessment scores: } \\
\text { I: } 3.4->4.3 \text {. C: } 3.6->4.1(\mathrm{p}=0,10) \text {. Separate data for } \\
\text { foot care not provided. }\end{array}$ \\
\hline Borges 2004 & No primary outcomes reported & $\begin{array}{l}\text { Patients' self-reported behaviour assessment scores: } \\
\mathrm{I}: 4,7->5.6(\mathrm{p}<0.01) . \text { RA: } 4.8 \rightarrow 5,2(\mathrm{p}=0.06) . \text { C: } 5.1 \\
\rightarrow 5.4(\mathrm{p}<0.05) \text {. } \\
\text { Observed self-care behaviour: } \\
4 \text { of } 16 \text { items significantly }(\mathrm{p}<0.05) \text { more observed in } \\
\text { I than in C. }\end{array}$ \\
\hline
\end{tabular}

Copyright $\odot 2010$ The Cochrane Collaboration. Published by John Wiley \& Sons, Ltd. 


\begin{tabular}{|c|c|c|}
\hline & & $\begin{array}{l}\text { Foot care knowledge scores: } \\
\text { Increased within the control group, but not in the } \\
\text { intervention or risk assessment groups. }\end{array}$ \\
\hline Corbett 2003 & No primary outcomes reported & $\begin{array}{l}\text { Foot care knowledge scores: } \\
\text { I: } 4.9->6.1 \text { vs C: } 4.6->5.2(p=0.03) \\
\text { Foot care practice scores: } \\
\text { I: } 4.3 \rightarrow 5.6 \text { vs C: } 4.1 \rightarrow 4.3(\mathrm{p}=0.007) \text {. }\end{array}$ \\
\hline Frank 2003 & No primary outcomes reported & 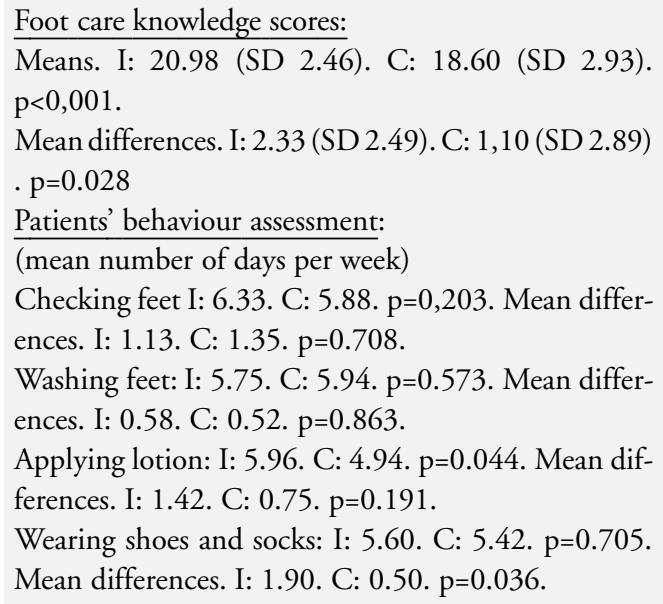 \\
\hline Kruger 1992 & No primary outcomes reported & 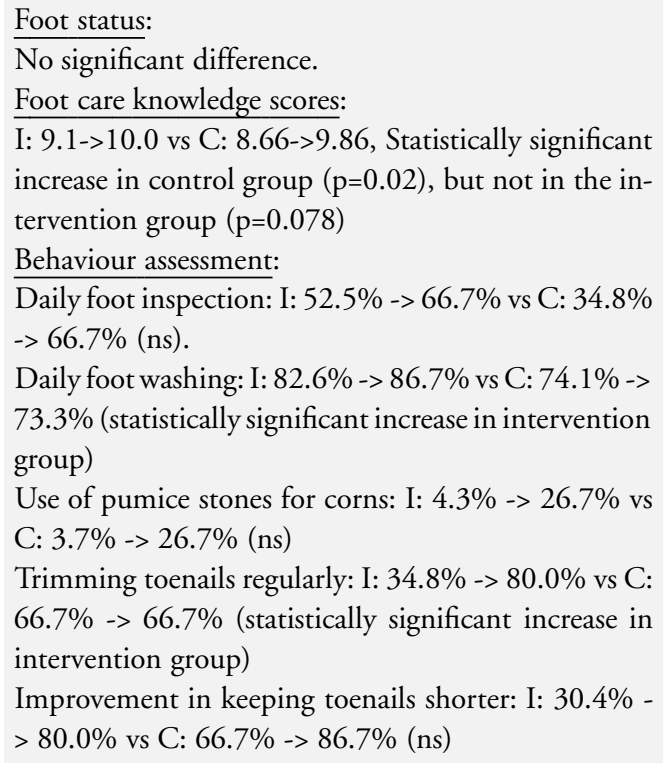 \\
\hline Lincoln 2008 & $\begin{array}{l}\text { Ulcer incidence: } \\
\text { After six months: I 26. C: } 18 \text {. RR: } 1.41 \text { (95\% CI } 0.84 \\
\text { to } 2.38) \text {. } \\
\text { After } 12 \text { months: I: } 36 . \text { C: } 35 \text {. RR: } 1.00 \text { ( } 95 \% \text { CI } 0.70\end{array}$ & $\frac{\text { Behaviour assessment scores: }}{\mathrm{I}: 42.0 . \mathrm{C}: 38.7 .(\mathrm{p}=0.03)}$ \\
\hline
\end{tabular}


Table 1. Results from trials (Continued)

\begin{tabular}{|c|c|c|}
\hline & $\begin{array}{l}\text { to } 1.44) \\
\text { Amputation rate: } \\
\text { After six months: I: 3. C: } 0 . \text { RR: not estimable. } \\
\text { After } 12 \text { months: I: 9. C: } 9 \text {. RR: } 0.98 \text { (95\% CI } 0.41 \\
\text { to } 2.34)\end{array}$ & \\
\hline Malone 1989 & $\begin{array}{l}\text { Ulcer incidence: } \\
\text { I: } 8 \text { vs C: } 26 \text {; significantly lower in intervention group } \\
\text { ( }<<=0.005) \text {. } \\
\text { Amputation rate: } \\
\text { I: } 7 \text { vs C: } 21 \text {; significantly lower in intervention group } \\
(\mathrm{p}<0.025) .\end{array}$ & No secondary outcomes reported. \\
\hline Mazzuca 1986 & No primary outcomes reported & $\frac{\text { Foot care knowledge scores: }}{\text { No significant difference }}$ \\
\hline Rettig 1986 & No primary outcomes reported & $\begin{array}{l}\text { Foot appearance scores: } \\
\text { I: } 70.2 \pm 0.7 \text { vs C: } 68.8 \pm 0.7 \text { (ns). } \\
\text { Foot care knowledge scores: } \\
\text { I: } 62.2 \pm 1.7 \text { vs C: } 53.1 \pm 1.8,(\mathrm{p}=0.001) \text {. Significant } \\
\text { increase in intervention group. } \\
\text { Foot care skills scores: } \\
\text { I: } 71.8 \pm 2.0 \text { vs C: } 68.9 \pm 1.8(\mathrm{~ns}) .\end{array}$ \\
\hline Rönnemaa 1997 & $\begin{array}{l}\text { Amputation: } \\
\text { One year follow-up: I 0. C } 0 . \\
\text { Seven years follow-up: I 1. C } 0 . \\
\text { Foot ulceration: } \\
\text { One year follow-up: I 1. C } 0 . \\
\text { Seven years follow-up: I 1. C } 1 .\end{array}$ & 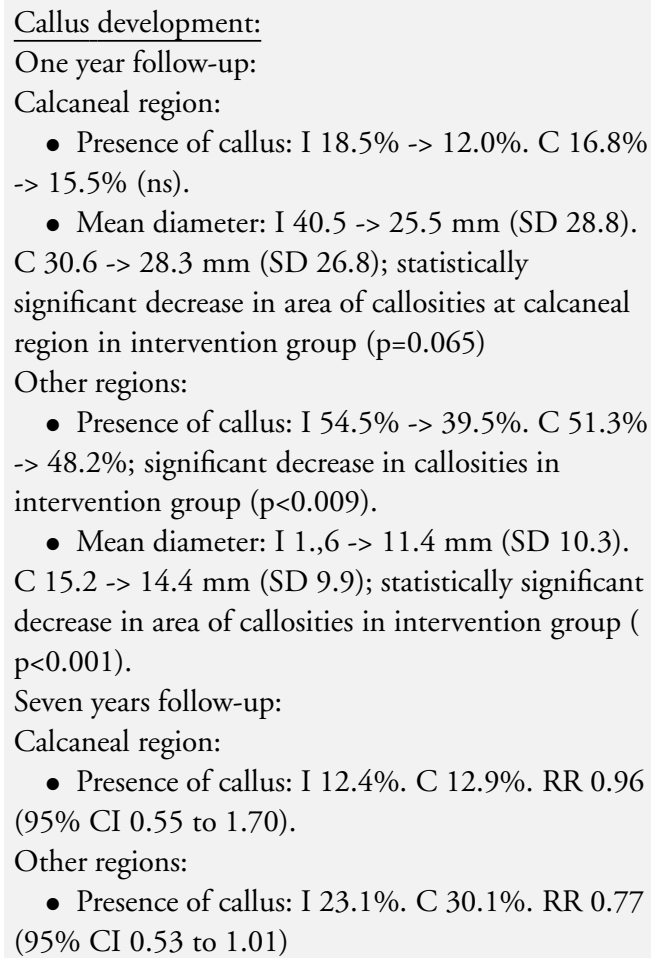 \\
\hline
\end{tabular}




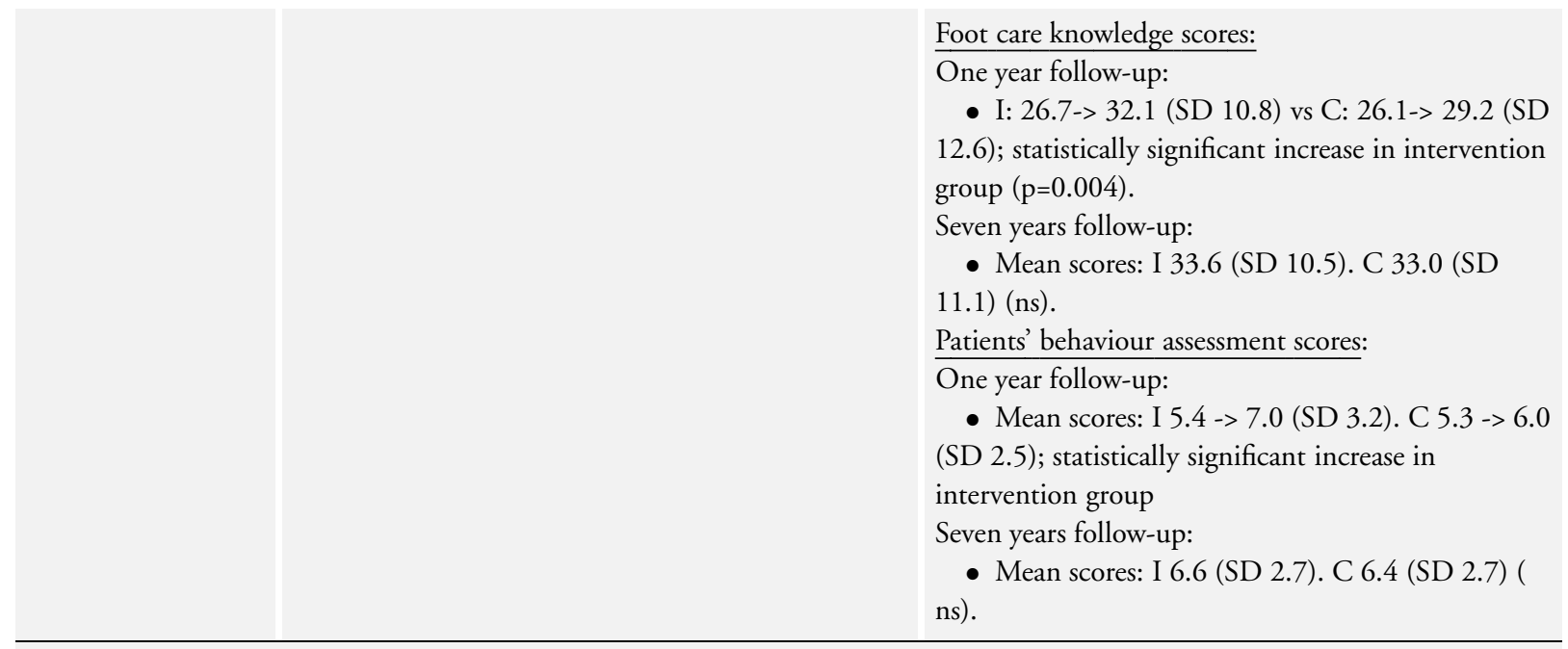

Abbreviations: $\mathrm{I}=$ intervention group, $\mathrm{C}=$ control group, $\mathrm{RA}=$ group that received risk assessment only, $\mathrm{n}=$ number of participants within group, $\mathrm{RR}=$ risk ratio, $\mathrm{SD}=$ standard deviation, $\mathrm{CI}=95 \%$ confidence interval, $\mathrm{p}=\mathrm{p}$-value, $\mathrm{ns}=$ no statistical significance.

We attempted to estimate pooled effect sizes of the primary outcomes of two seemingly similar studies (Lincoln 2008; Malone 1989), but this was precluded by inconsistencies in the unit of analysis (one analysed the number of limbs and the other the number of people), unequal methodological quality and considerable statistical heterogeneity. Pooling of the remaining studies was not attempted because of considerable clinical heterogeneity.

\section{Foot care education as part of general diabetes education compared with usual care ( 3 RCTs)}

\section{Primary outcomes}

The incidence of foot ulceration or amputation was only reported in Bloomgarden 1987: 146 patients had no foot lesion at the initial evaluation and since only 2 severe foot lesions (ulceration or amputation) were observed in both the intervention and the control group during follow up of approximately 1.5 years, the effect was not significant. Also in the subgroup of patients with callus, nail dystrophy or fungal infection at baseline $(\mathrm{n}=100)$ and in the subgroup of patients with a previous ulcer or amputation at baseline $(n=20)$, no significant effects of the intervention were observed.

\section{Secondary outcomes}

After six months follow-up, Rettig 1986 reported that foot care knowledge scores were significantly higher in the intervention group (mean score: $62+/-1.7)$ compared with the control group (mean score: $53+/-1.8)(\mathrm{p}=0.001)$, but this had not resulted in positive effects on foot appearance and foot care skills score. Mazzuca 1986 reported no significant improvements in foot care knowledge, and Bloomgarden 1987 found no significant improvements in behaviour assessment scores, nor in the occurrence of callus, fungal infection and nail dystrophy.

It should be noted that in both Mazzuca 1986 and Bloomgarden 1987, adherence to the intervention and follow-up were poor. In Mazzuca 1986, only 52\% of patients were followed-up, and only $67 \%$ of patients requiring foot care completed treatment. Bloomgarden 1987 reported that $77 \%$ of patients who gave consent completed follow-up, but only $50 \%$ of patients in the intervention group adhered to the intervention. Rettig 1986 did not report adherence to the intervention.

\section{Foot care education tailored to educational needs compared with no intervention ( 2 RCTs)}

\section{Primary outcomes}

Not reported in any of the included RCTs.

\section{Secondary outcomes}


After a 10 to 20 minute individualised foot care education session at home, Corbett 2003 found that participants in the intervention group $(\mathrm{n}=19)$ had significantly greater foot care knowledge $(\mathrm{p}=$ $0.03)$ and improved self-care practices $(\mathrm{p}=0.007)$ compared with participants in the control group $(\mathrm{n}=16)$. This study, however, was limited by a small sample size and short duration of follow-up (six weeks). In Borges 2004, self-reported behaviour assessment scores were significantly improved after one month of follow-up in both the intervention group, who received a 15 minute education session $(\mathrm{p}<0.01)$, and in the control group, who received no intervention at all $(\mathrm{p}<0.05)$. Four of 16 foot self-care behaviours were significantly more frequently observed in the intervention group compared with the control group. Paradoxally, foot care knowledge increased only in the control group but not in the intervention group.

\section{Intensive compared with brief educational interventions (6 RCTs)}

\section{Primary outcomes}

In Malone 1989, 34 foot ulcers, 28 lower-extremity amputations and 4 foot infections were observed during 1 year of follow-up of 182 patients. A marked reduction in ulcer incidence (I: 8; C: 26) and amputation rate (I: 7;C: 21 ) was observed in the intervention group. It should be noted, however, that outcomes were reported per limb $(\mathrm{n}=354)$ instead of per patient $(\mathrm{n}=182)$. Therefore, a single participant could have had two events, although multiple events on the same limb were reported as one. This may have resulted in overestimation of the effect sizes and confidence intervals presented in Analysis 1.1, and Analysis 1.3.

These findings were not reproduced in the study by Lincoln 2008 , in which 71 foot ulcers and 18 lower-extremity amputations were observed during one year follow-up of 172 patients. No effects of the intervention on primary outcomes were observed at all. The relative risk for foot ulceration was 1.00 (95\% CI 0.70 to 1.44 , Analysis 1.2) and the relative risk for lower extremity amputation was 0.98 (95\% CI 0.41 to 2.34, Analysis 1.4).

In Rönnemaa 1997 ulcerations and amputations were reported, but these occurred too infrequently to be evaluated conclusively.

\section{Secondary outcomes}

In Lincoln 2008 a statistically significant increase in patients' behaviour assessment scores was reported in the intervention group ( $\mathrm{p}=0.03$ ), but for this outcome only $72 \%$ of patients were followed-up. Moreover, the authors questioned the reliability of their assessment tool.

Rönnemaa 1997 found a significant increase in foot care knowledge in the intervention group after one year of follow-up ( $\mathrm{p}=$ 0.004). Also patients' behaviour assessment scores (5.4 increased to 7.0 ), the mean diameter of callosities (calcaneal region 40.5 $\mathrm{mm}$ decreased to $25.5 \mathrm{~mm}, \mathrm{p}=0.065$; other regions $16.6 \mathrm{~mm}$ decreased to11.4 mm, $\mathrm{p}<0,001)$ and the presence of callus in other regions than the calcaneal region $(54.4 \%$ decreased to $39.5 \%$, $\mathrm{p}<0.009)$ initially improved after the intervention. However, after seven years of follow-up, the control group had made up all these arrears.

In Frank 2003, foot care knowledge was marginally but significantly better in the intervention than in the control group, four weeks after the educational intervention. Adherence to one of the four daily foot care behaviours studied (wearing shoes and socks) was significantly more improved in the intervention group than in the control group, but this did not account for adherence to the other three foot care behaviours studied (checking feet, washing and drying feet, applying lotion).

In Barth 1991, already after one month of follow-up a significant reduction of foot problems requiring treatment $(\mathrm{p}<0.001)$ and an increase in foot care routine compliance $(\mathrm{p}<0.001)$ was seen in the intervention group. Also foot care knowledge improved in both groups, but most in the intervention group $(\mathrm{p}<0.001)$. Improvements were maintained until after six months of follow-up, but the differences between intervention and control group diminished. Kruger 1992 also found almost similar improvements of foot care knowledge scores in both the intervention and control group (I: 9.1 increased to 10.0 and C: 8.7 increased to 9.9) and no significant differences in the status of patients' feet after six months of follow-up. Some (daily foot washing, trimming of toenails), but not all foot care behaviours (daily foot inspection, use of pumice stones, keeping toenails shorter) improved in the intervention group. However, this study dealt with small groups (23 patients in the intervention group and 27 in the control group), and also had a relatively high dropout rate (40\%).

\section{DISCUSSION}

\section{Summary of main results}

A wide range and combinations of patient educational interventions have been evaluated for the prevention of diabetic foot ulceration. These interventions varied from brief patient education to intensive patient education including demonstration and 'handson' teaching.

The ultimate aim of foot care education for people with diabetes is to prevent foot ulceration and amputations. However, these endpoints were assessed in only four of the 11 RCTs. The results of this review are presented in a study-by-study qualitative synthesis. Pooling of the results was precluded by marked heterogeneity (mainly clinical), because participants, types of interventions, types of control interventions, outcome measures, outcome assessment tools, duration of follow-up and risk of bias varied widely between studies. 
Only one RCT showed that, after one year follow-up, the incidence of foot ulcers and amputations was lower in the patient group who received one hour of group education on the diabetic foot by a podiatrist compared with the patient group who received routine foot care education (Malone 1989). In this RCT, the number of legs instead of the number of patients was taken as the unit of analysis (so-called 'unit of analysis error') leading to an overestimation of the precision of the study and thus the ability to reach statistical significance. Moreover, an inadequate quasirandomised method was used for group allocation and it was not clear if baseline variables were comparable. Also, blinding of the outcome assessor and co-interventions were not reported and intention to treat analysis was not attempted (Malone 1989). More importantly, the positive findings of this study are contradicted by the results of a more recent study that was included in this review (Lincoln 2008), which also studied a population at high risk for foot ulceration. Most other characteristics of this study were similar to Malone 1989 too, although regular care, that was available to both the intervention and the control groups of both studies might have improved between 1989 and 2008 when the latter study was published. It can be argued that in Lincoln 2008, the educational intervention and the control intervention did not contrast enough to result in significantly different outcomes. Nevertheless, the risk of bias in Lincoln 2008 was very low. This study concluded that a single hour of patient education compared with written instructions only had no beneficial effects on the incidence of foot ulceration and amputation rate after 12 months of followup. The other two RCTs which reported the effect of patient education on foot ulceration and amputation demonstrated no effect either (Bloomgarden 1987; Rönnemaa 1997). However, the overall event-rate in the populations studied showed that these two studies were underpowered to show any effect on these primary outcome measures.

The present review demonstrates a positive short-term effect of education on patients' foot care knowledge, which improved in five of the eight RCTs in which this outcome was assessed (Barth 1991; Corbett 2003; Frank 2003; Rettig 1986; Rönnemaa 1997). However, in the one RCT with longer follow up, the difference in foot care knowledge between intervention and control group had disappeared at seven years (Rönnemaa 1997). Similarly patients' behaviour at 6 to 18 months improved in seven of the nine RCTs in which this outcome was assessed (Barth 1991; Borges 2004; Corbett 2003; Frank 2003; Kruger 1992; Lincoln 2008; Rönnemaa 1997). Although behaviour assessment scores were still improved after seven years of follow-up compared with the baseline measurements, the control group had made up arrears (Rönnemaa 1997). The assessment tools for measuring foot care knowledge and self-care behaviour varied between studies, because there is currently no single standardised validated tool widely used for these purposes. We were therefore unable to evaluate the importance (clinical relevance) of the reported statistically significant improvements in foot care knowledge scores and self-care behaviour assessment scores.

The effects on callus, nail problems and/or fungal infections were described in five studies. In only two of them were some positive effects at short term follow-up reported (Barth 1991; Rönnemaa 1997), but the differences between intervention and control group were not maintained until final follow-up. In three additional studies no benefit on these outcomes was achieved at all (Bloomgarden 1987; Kruger 1992; Rettig 1986). It may be possible that co-interventions, such as podiatry care, influenced these outcomes. In Rönnemaa 1997 podiatry care was part of the experimental intervention. Therefore, patients in the intervention group were reported to have seen a podiatrist more often (mean number of visits: 4.7) than patients in the control group (mean number of visits 0.4 ) after one year of follow-up, and consequently an improvement on callus, nail problems and fungal infections was reported in the intervention group. During the last year of follow-up, only 30.8\% of the patients in the intervention group still visited a podiatrist compared with $25.2 \%$ of the control group patients. The initial advantage of the intervention group had disappeared. A similar explanation accounts for the initial benefit of the intervention group in Barth 1991: after one month of follow-up, 17 patients in the intervention group compared with seven in the control group had consulted a podiatrist. Between the third and sixth month of follow up, these figures levelled to seven and eight patients in each group. These examples show the importance of adequate reporting of co-interventions, which was one of the shortcomings of the other three studies which reported these outcomes.

\section{Overall completeness and applicability of evidence}

The studies in this review which included patients with diabetes at low or medium risk for foot ulceration recruited too few participants and followed them up for too short a period of time to be able to detect clinically important differences in primary outcomes. For example, in order to detect a $50 \%$ reduction in the incidence of diabetic foot ulceration, 430 to 870 patients would be required per treatment group (based on an annual incidence of foot ulceration in the general diabetes population of 2 to $4 \%$ per year or 4 to $8 \%$ over two years) (De Sonnaville 1997; Reenders 1993). The mean size of studies in this review which included patients at low or medium risk for foot ulceration was 138 patients per treatment group, ranging from 25 (Kruger 1992) to 266 (Mazzuca 1986) and with six months median time to follow-up , indicating that none of these studies were actually sufficiently powered to detect differences in the long term on one of the primary outcomes. Unfortunately, the trials included in this review do not share a common set of characteristics (participants, educational methods, intensity of education to intervention and the control group, outcome measures, duration of follow-up), thereby hindering present and future pooling. 
Two studies reported the effect of foot care education on primary outcomes in a population at high risk (Lincoln 2008; Malone 1989). These RCTs were well-powered, but studied the effect of a very limited educational programme, comprising only a single one hour educational session, reinforced by handouts, compared with either routine patient education (Malone 1989) or written instructions only (Lincoln 2008). The conclusions of these studies were contradictory, but because the risk of bias was lower in Lincoln 2008, more weight should be given to the outcomes of this study. It shows that a limited educational intervention is not likely to result in improvement of ulcer incidence and amputation incidence. This, however, does not rule out effectiveness of more comprehensive and/or more intensive educational strategies, but these strategies were not studied.

In summary, evidence on the effectiveness of comprehensive and intensive patient education programmes to prevent diabetic foot ulceration is still needed. Below we make suggestions for future research (Implications for research).

\section{Quality of the evidence}

One of the most important findings of the present review is the high or unclear risk of bias in all but one of the included RCTs. This was mainly caused by insufficient reporting. Usually methodological flaws lead to an overestimation of the effect size. Therefore, the few positive effects that were found should be interpreted with caution. On the other hand, unknown and unregistered cointerventions in the control groups of the included trials (e.g. podiatry care, unstructured patient education by the care provider) could have led to reductions in the effects of the experimental educational interventions. Finally, it must be stressed that foot care knowledge and patient behaviour were measured using subjective outcome measures and are therefore also prone to bias.

\section{Potential biases in the review process}

The clinical heterogeneity of the RCTs meant it was not possible to make a funnel-plot to assess the presence of publication bias. However, in general, publication bias would be likely to lead to an overestimation of the effects. In this review, most of the RCTs identified reported non-significant findings and it is therefore unlikely that we overestimated any effect.

The availability of co-interventions to participating patients of the intervention and the control group may have influenced the outcomes of the trials in this review. For example, in Rönnemaa 1997 and Barth 1991 the incidence of callus, nail problems and fungal infection were probably influenced by the availability of podiatry care (see Summary of main results). In most other studies, it is not reported which co-interventions were available and whether they have influenced the outcomes. Furthermore, 'care as usual' has greatly improved and must no longer be mistaken for 'doing nothing' Therefore, a limited educational intervention may add little to the existing knowledge of patients to result in any beneficial effects. This especially accounts for more recent studies like Lincoln 2008.

The studies included in this review used different tools to assess care knowledge and self-care behaviour. Therefore, it was not possible to evaluate the importance (clinical relevance) of the reported statistically significant improvements in foot care knowledge scores and self-care behaviour assessment scores. Foot care knowledge improved to some extent in five of eight studies, but consequently, this does not provide proof of effectiveness.

\section{Agreements and disagreements with other studies or reviews}

The conclusions of this systematic review contrast with those in earlier reviews on this topic (Armstrong 1998; Assal 1985; Bild 1989; Boulton 1995; Bowering 2001; Edmonds 1996; Larsson 1995; Levin 1995; Majid 2000; Mason 1999; Mayfield 1998; Rith-Najarian 2000; Singh 2005; Wu 2007). According to these review articles, there was enough evidence to support the effectiveness of patient education for the prevention of diabetic foot ulceration. This systematic review of randomised controlled trials, however, provides a more complete and well-considered overview of the available evidence, incorporating an evaluation of the risk of bias of the included studies.

This review was written in close conjunction with another review on the effectiveness of complex interventions for preventing diabetic foot ulceration (Dorresteijn 2010). That review included only five RCTs which were at high or unclear risk of bias. In agreement with this review, it was concluded that there is also no of evidence to support the effectiveness of a multi-level integrated care approach for the prevention of diabetic foot ulceration (complex intervention, some of which included patient education), although this should be interpreted as a lack of evidence rather than evidence of no effect.

The RCTs included in this review show the same shortcomings as the RCTs included in a recent systematic review about the effectiveness of individual patient education for improvement of general metabolic control of patients with diabetes mellitus (Duke 2009). The RCTs in that review were also small and had too many methodological flaws from which to draw firm conclusions. This underlines our recommendations for future research below (Implications for research).

\section{AUTHORS' CONCLUSIONS}

\section{Implications for practice}

Overall, it appears that little evidence is available to support the effectiveness of patient education for the prevention of diabetic foot 
ulceration or amputations. The RCTs which have been conducted on the topic of patient education for preventing diabetic foot ulceration are generally underpowered and at high or unclear risk of bias. Consequently, whilst some results are suggestive of positive effects, this must be viewed with caution. Foot care knowledge and patient behaviour seem to be positively influenced by education in the short-term, but the ultimate goal of educational interventions (improving knowledge and behaviour) is preventing foot ulceration and amputation. One RCT with good methodological quality showed that limited patient education did not result in any beneficial effect on these primary outcomes. The effectiveness of more comprehensive and/or more intensive educational programmes, however, remains to be further investigated.

\section{Implications for research}

More randomised trials that evaluate the effect of intensive patient education programmes for the prevention of diabetic foot ulceration are urgently needed, because the evidence in this field does not allow us to draw firm conclusions. Researchers should realise that standard care nowadays usually already includes basic and unstructured patient education on the diabetic foot. Therefore, it is unlikely that limited education will markedly improve clinical outcome. Thus, experimental educational interventions should clearly contrast with standard education and the content of 'usual care' that is provided to the control group should be explicitly described. The main shortcomings of the studies included in this review are: (1) insufficient power and duration of followup to detect clinically relevant improvements in foot ulceration and amputation incidence, (2) marked clinical heterogeneity and (3) high risk of bias.

First, the ultimate aim of preventive strategies is to reduce the incidence of foot ulceration. This means that randomised trials which include diabetes patients at average risk for foot ulceration need at least 430 to 870 patients per treatment arm in order to detect a $50 \%$ reduction in the incidence of foot ulceration (based on an annual incidence of foot ulceration in the general diabetes population of 2 to $4 \%$ per year or 4 to $8 \%$ over two years) (Reenders 1993; De Sonnaville 1997). For studies including patients at high risk for foot ulceration, fewer participants are needed. Most RCTs included in this review were underpowered to show any effects of the intervention on amputation and/or foot ulceration incidence.

Secondly, in order to facilitate proper analysis and future comparison of the results of studies evaluating the effects of patient education programmes, more homogeneity of study characteristics and study reporting is needed. To begin with, particular consideration should be given to adequate reporting of baseline values and criteria for exclusion and inclusion (Reed 2005). To facilitate reproducibility of future RCTs on this topic and to enable comparison and pooling of similar studies, standardising patient education on the diabetic foot by formulating clear and commonly accepted learning objectives is recommended (Colagiuri 2009). As stated, the content of 'usual care' that is provided to the control group should also be explicitly described. Furthermore, all future RCTs studying the effect of patient education for preventing diabetic foot ulceration should at least report the incidence of foot ulceration and amputation. An outline of the costs associated with each intervention is vital to assess cost-effectiveness. If changes in patients' foot care knowledge and self-care behaviour are reported, these should be measured with standardised and validated tools. However, such standard sets of outcomes, like those available in rheumatology research (OMERACT) and low back pain research (Deyo 1998), still need to be developed for research on the diabetic foot.

Thirdly, efforts must be made to reduce risk of bias and poor reporting of future studies. Patients should be randomised properly according to an adequately generated randomisation sequence and with concealed allocation. Blinding of patients and health care providers is often not possible due to the nature of the intervention, but blinding of outcome assessors must be ensured. Also, more pragmatic study design options like the Zelen's design (in which the control group is not informed) might be an option (Schellings 2005). Co-interventions need to be registered and reported accurately. Furthermore, loss to follow-up should be avoided because this may lead to underestimation of the intervention results. If loss to follow-up is notable, reasons for study withdrawal should be reported in order to reveal any causality. Finally, RCTs must be reported in accordance with CONSORT guidelines (Schultz 2010) and its extension to cluster randomised trials (Campbell 2004).

We realise that trials of this magnitude are costly, but the benefits in terms of potential reduction in costs associated with effective treatment are potentially significant. Still, since most of the RCTs in this review with low risk of bias did not find any positive effects or only marginal improvements, it may be that patient education alone is not sufficient for achieving clinically relevant risk reductions. Therefore above all, we recommend the study of the effect of educational interventions when combined with other interventions for the prevention of diabetic foot ulceration (complex interventions). In Dorresteijn 2010, an overview is provided of the existing RCTs on complex interventions for the prevention of diabetic foot ulceration.

\section{ACKNOWLEDGEMENTS}

The authors would like to thank:

- Nicky Cullum for putting her existing work on education for the diabetic foot at our disposal.

- The Cochrane Wounds Group referees (Neil Baker, Althea Foster, Sue O'Meara, Jude Smith) and editors (Nicky Cullum, Andrew Jull) who commented on the original review. 
- Sally Stapley who helped coordinate the latest update of this review.

\section{REFERENCE S}

\section{References to studies included in this review}

\section{Barth 1991 \{published data only\}}

* Barth R, Campbell LV, Allen S, Jupp JJ, Chisholm DJ. Intensive education improves knowledge, compliance and foot problems in type 2 diabetes. Diabetic Medicine 1991;8:111-17.

\section{Bloomgarden 1987 \{published data only\}}

* Bloomgarden ZT, Karmally W, Metzger MJ, Brothers M, Nechemias C, Bookman J, et al.Randomized controlled trial of diabetic patient education: improved knowledge without improved metabolic status. Diabetes Care 1987;10(3):263-72.

\section{Borges 2004 \{published data only\}}

* Borges WJ. The impact of a brieffoot care intervention for persons with diabetes. University of Texas Health Science Center at Houston School of Nursing, doctoral dissertation (249p), 2004 Borges WJ, Ostwald SK. Improving foot self-care behaviors with Pies Sanos. Western Journal of Nursing Research 2008 Apr;30(3): $325-41$.

\section{Corbett 2003 \{published and unpublished data\}}

* Corbett CF. A randomized pilot study of improving foot care in home health patients with diabetes. The Diabetes Educator 2003; 29:273-82.

\section{Frank 2003 \{published data only\}}

* Frank KI. Self-management of foot care for patients 65 years of age or older with diabetes. Indiana University School of Nursing 2003 Dec.

Kruger 1992 \{published data only\}

* Kruger S, Guthrie D. Foot care: knowledge retention and selfcare practices. The Diabetes Educator 1992;18(6):487-90.

Lincoln 2008 \{published data only\}

* Lincoln NB, Radford KA, Game FL, Jeffcoate WJ. Education for secondary prevention of foot ulcers in people with diabetes: a randomised controlled trial. Diabetologia 2008 Nov;51(11): 1954-61.

Malone 1989 \{published data only\}

* Malone JM, Snyder M, Anderson G, Bernhard VM, Holloway GA, Bunt TJ. Prevention of amputation by diabetic education. The American Journal of Surgery 1989;158:520-4.

Mazzuca 1986 \{published and unpublished data\}

* Mazzuca SA, Moorman NH, Wheeler ML, Norton JA, Fineberg NS, Vinicor F, et al.The diabetes education study: a controlled trial of the effects of diabetes patient education. Diabetes Care 1986;9 (1):1-10.

Rettig 1986 \{published data only\}

* Rettig BA, Shrauger DG, Recker RR, Gallagher TF, Wiltse H. A randomized study of the effects of a home diabetes education program. Diabetes Care 1986;9(2):173-8.
Rönnemaa 1997 \{published and unpublished data\}

Hämäläinen H, Rönnemaa T, Toikka T, Liukkonen I. Long-term effects of one year of intensified podiatric activities on foot-care knowledge and self-care habits in patients with diabetes. The Diabetes Educator 1998;24(6):734-40.

* Rönnemaa T, Hämäläinen H, Toikka T, Liukkonen I. Evaluation of the impact of podiatrist care in the primary prevention of foot problems in diabetic subjects. Diabetes Care 1997;20(12):1833-7. Rönnemaa T, Liukkonen I, Knuts L-R, Seppälä P, Kallio V. Prevalence of foot problems and need for foot care in an unselected diabetic population. The Journal of British Podiatric Medicine 1993 Dec;48(12):185-90.

\section{References to studies excluded from this review}

Dargis 1999 \{published data only\}

* Dargis V, Pantelejeva O, Jonushaite A, Vileikyte L, Boulton AJM. Benefits of a multidisciplinary approach in the management of recurrent diabetic foot ulceration in Lithuania - a prospective study. Diabetes Care 1999;22:1428-31.

Davidson 2000 \{published data only\}

* Davidson MB, Karlan VJ, Hair TL. Effect of a pharmacistmanaged diabetes care program in a free medical clinic. American Journal of Medical Quality 2000;15:137-41.

De Weerdt 1991 \{published data only\}

* Weerdt I de, Visser AP, Kok GJ, Weerdt O de, Veen EA van der. Randomized controlled multicentre evaluation of an education programme for insulin-treated diabetic patients: effects on metabolic control, quality of life, and costs of therapy. Diabetic Medicine 1990;8:338-45.

Donohoe 2000 \{published data only\}

* Donohoe ME, Fletton JA, Hook A, Powell R, Robinson I, Stead JW, et al.Improving foot care for people with diabetes mellitus - a randomized controlled trial of an integrated care approach. Diabetic Medicine 2000;17:581-7.

Glasgow 1992 \{published data only\} * Glasgow RE, Toobert DJ, Hampson SE, Brown JE, Lewinsohn PM, Donnelly J. Improving self-care among older patients with type II diabetes: the 'sixty something...' study. Patient Education and Counseling 1992;19:61-74.

Litzelman 1993 \{published data only\}

* Litzelman DK, Slemenda CW, Langeveld CD, Hays LM, Welch MA, Bild DE, et al.Reduction of lower extremity clinical abnormalities in patients with non-insulin-dependent diabetes mellitus. Annals of Internal Medicine 1993;119(1):36-41.

Litzelman 1997 \{published data only\}

* Litzelman DK, Marriot DJ, Vinicor F. The role of footwear in the prevention of foot lesions in patients with NIDDM. Diabetes Care 1997;20(2):156-62. 
McCabe 1998 \{published data only\}

* McCabe CJ, Stevenson RC, Dolan AM. Evaluation of a diabetic foot screening and protection programme. Diabetic Medicine 1998; 15:80-4.

McMurray 2002 \{published data only\}

* McMurray SD, Johnson G, Davis S, McDougall K. Diabetes education and care management significantly improve patient outcomes in the dialysis unit. American Journal of Kidney Diseases 2002;40:566-75.

McMurray SD, McDougall K. Improving Diabetes Foot Care in the Dialysis Facility. Nephrology News \& Issues 2003;17(10):57, 60$1,65-6$.

Pieber 1995 \{published data only\}

* Pieber TR, Holler A, Siebenhofer A, Brunner GA, Semlitsch B, Schattenberg $S$, et al.Evaluation of a structured teaching and treatment programme for type 2 diabetes in general practice in a rural area of Austria. Diabetic Medicine 1995;12:349-54.

Plank 2003 \{published data only\}

* Plank J, Haas W, Rakovac I, Gorzer E, Sommer R, Siebenhofer A, et al.Evaluation of the impact of chiropodist care in the secondary prevention of foot ulcerations in diabetic subjects. Diabetes Care 2003;26:1691-5.

Reichard 1993 \{published data only\}

* Reichard P, Nilsson BY, Rosenqvist U. The effect of long-term intensified insulin treatment on the development of microvascular complications of diabetes mellitus. The New England Journal of Medicine 1993;329(5):304-9.

Schiel 2004 \{published data only\}

* Schiel R, Braun A, Müller R, Helbich C, Siefke S, Franke I, et al.A structured treatment and educational program for patients with type 2 diabetes mellitus, insulin therapy and impaired cognitive function (DikoL) [Ein strukturiertes behandlung-und schulungsprogramm für patienten mit typ-2-diabetes mellitus, insulintherapie und verminderten kognitiver leistungsfähigkeit (DikoL)]. Medizinische Klinik 2004 Jun;99(6):285-92.

Vinicor 1985 \{published data only\}

* Vinicor F, Cohen SJ, Mazzuca SA, Moorman N, Wheeler M, Kuebler T, et al.Diabeds: a randomized trial of the effects of physician and/or patient education on diabetes patient outcomes. Journal of Chronic Disease 1987;40(4):345-56.

Ward 1999 \{published data only\}

* Ward A, Metz L, Oddone EZ, Edelman D. Foot education improves knowledge and satisfaction among patients at high risk for diabetic foot ulcer. The Diabetes Educator 1999;25(4):560-7.

\section{Wooldridge 1996 \{published data only\}}

* Wooldridge J, Bergeron J, Thornton C. Preventing diabetic foot disease: lessons from the medicare therapeutic shoe demonstration. American Journal of Public Health 1996;86(7):935-8.

\section{Additional references}

\section{American Diabetes Association 2007}

American Diabetes Association. Standards of medical care in diabetes - 2007. Diabetes Care 2007 Jan;30(Suppl 1):S4-S41.
Apelqvist 1993

Apelqvist J, Larsson J, Agardh CD. Long-term prognosis for diabetic patients with foot ulcers. Journal of Internal Medicine 1993;233:485-91.

\section{Armstrong 1998}

Armstrong DG, Lavery LA. Diabetic foot ulcers: prevention, diagnosis and classification. American Family Physician 1998;57: $1325-32$.

\section{Assal 1985}

Assal JP, Mühlhauser I, Pernet A, Gfeller R, Jörgens V, Berger M. Patient education as the basis for diabetes care in clinical practice and research. Diabetologia 1985;28:602-13.

\section{Bild 1989}

Bild DE, Selby JV, Sinnock P, Browner WS, Braveman P, Showstack JA. Lower-extremity amputation in people with diabetes. Epidemiology and prevention. Diabetes Care 1989;12:24-31.

\section{Boulton 1995}

Boulton AJM. Why bother educating the multi-disciplinary team and the patient - the example of prevention of lower extremity amputation in diabetes. Patient Education and Counseling 1995;26: $183-8$.

\section{Boulton 2004}

Boulton AJ, Kirsner RS, Vileikyte L. Clinical practice. Neuropathic diabetic foot ulcers. The New England Journal of Medicine $2004 \mathrm{Jul}$ 1;351(1):48-55.

\section{Boulton 2005}

Boulton AJ, Vileikyte L, Ragnarson-Tennvall G, Apelqvist J. The global burden of diabetic foot disease. Lancet 2005 Nov 12;366 (9498):1719-24.

\section{Bowering 2001} Bowering CK. Diabetic foot ulcers. Pathophysiology, assessment, and therapy. Canadian Family Physician 2001 May;47:1007-16.

\section{Campbell 2004}

Campbell MK, Elbourne DR, Altman DG, CONSORT group. CONSORT statement: extension to cluster randomised trials. BMJ 2004 Mar 20;328(7441):702-8.

\section{Canavan 2008}

Canavan RJ, Unwin NC, Kelly WF, Connolly VM. Diabetes- and nondiabetes-related lower extremity amputation incidence before and after the introduction of better organized diabetes foot care: continuous longitudinal monitoring using a standard method. Diabetes Care 2008 Mar;31(3):459-63.

\section{Cavanagh 2005} Cavanagh PR, Lipsky BA, Bradbury AW, Botek G. Treatment for diabetic foot ulcers. Lancet 2005 Nov 12;366(9498):1725-35.

\section{Colagiuri 2009}

Colagiuri R, Eigenmann CA. A national consensus on outcomes and indicators for diabetes patient education. Diabetic Medicine 2009 Apr;26(4):442-6.

\section{De Sonnaville 1997}

De Sonnaville JJ, Colly LP, Wijkel D, Heine RJ. The prevalence and determinants of foot ulceration in type 2 diabetic patients in a primary health care setting. Diabetes Research and Clinical Practice 1997;35:149-56 


\section{Deyo 1998}

Deyo RA, Battie M, Beurskens AJ, Bombardier C, Croft P, Koes B, et al.Outcome measures for low back pain research. A proposal for standardized use. Spine 1998 Sep 15;23(18):2003-13.

\section{Dinh 2005}

Dinh TL, Veves A. A review of the mechanisms implicated in the pathogenesis of the diabetic foot. The International Journal of Lower Extremity Wounds 2005 Sep;4(3):154-9.

\section{Dorresteijn 2010}

Dorresteijn JAN, Kriegsman DMW, Valk GD. Complex interventions for preventing diabetic foot ulceration. Cochrane Database of Systematic Reviews 2010, Issue 1. [DOI: 10.1002/ 14651858.CD007610.pub2]

Duke 2009

Duke SA, Colagiuri S, Colagiuri R. Individual patient education for people with type 2 diabetes mellitus. Cochrane Database of Systematic Reviews 2009 Jan 21, Issue 1. [DOI: 10.1002/ 14651858.CD005268.pub2]

\section{Edmonds 1996}

Edmonds ME, Van Acker K, Foster AVM. Education and the diabetic foot. Diabetic Medicine 1996;13:S61-S64.

\section{Edmonds 2006}

Edmonds ME, Foster AV. Diabetic foot ulcers. BMJ 2006 Feb 18; 332(7538):407-10.

\section{Frykberg 2006}

Frykberg RG, Zgonis T, Armstrong DG, Driver VR, Giurini JM, Kravitz SR, et al.Diabetic foot disorders. A clinical practice guideline (2006 revision). The Journal of Foot and Ankle Surgery 2006 Sep-Oct;45(5 Suppl):S1-66.

\section{Gibson 2002}

Gibson PG, Coughlan J, Wilson AJ, Hensley MJ, Abramson M, Bauman A, et al.The effects of limited (information only) patient education programs on the health outcomes of adults with asthma. Cochrane Database of Systematic Reviews 2002, Issue 1. [DOI: 10.1002/14651858.CD001005]

Global Lower Extremity Amputation Study Group 2000 Global Lower Extremity Amputation Study Group. Epidemiology of lower extremity amputation in centres in Europe, North America and East Asia. The British Journal of Surgery 2000 Mar;87(3): $328-37$.

\section{Haines 2009}

Haines T, Gross A, Burnie SJ, Goldsmith CH, Perry L. Patient education for mechanical neck disorders. Cochrane Database of Systematic Reviews 2009, Issue 1. [DOI: 10.1002/ 14651858.CD005106.pub3]

\section{Higgins 2008}

Jonathan J Deeks, Julian PT Higgins and Douglas G Altman on behalf of the Cochrane Statistical Methods Group (editors). Chapter 8: Assessing risk of bias in included studies. In: Higgins JPT, Green S (editors), Cochrane Handbook for Systematic Reviews of Interventions Version 5.0.0 (updated February 2008). Available from www.cochrane-handbook.org. The Cochrane Collaboration, 2008.

Icks 2009

Icks A, Haastert B, Trautner C, Giani G, Glaeske G, Hoffmann F. Incidence of Lower-limb Amputations in the Diabetic Compared to the Non-diabetic Population. Findings from Nationwide Insurance Data, Germany, 2005-2007. Experimental and Clinical Endocrinology and Diabetes 2009 Oct;117(9):500-4.

\section{IDF clinical guidelines task force 2005} IDF clinical guidelines task force. Global guideline for type 2 diabetes. Brussels: International Diabetes Federation 2005.

\section{Jeffcoate 2003}

Jeffcoate WJ, Harding KG. Diabetic foot ulcers. Lancet 2003 May 3;361(9368):1545-51.

\section{Larsson 1995}

Larsson J, Apelqvist J. Towards less amputations in diabetic patients. Incidence, causes, cost, treatment, and prevention - a review. Acta Orthopaedica Scandinavica 1995;66:181-92.

\section{Lefebvre 2008}

Lefebvre C, Manheimer E, Glanville J, on behalf of the Cochrane Information Retrieval Methods Group. Chapter 6: Searching for studies. In: Higgins JPT, Green S (editors). Cochrane Handbook for Systematic Reviews of Interventions Version 5.0.1 (updated September 2008). The Cochrane Collaboration, 2008. Available from www.cochrane-handbook.org.

Levin 1995

Levin ME. Preventing amputation in the patient with diabetes. Diabetes Care 1995;18:1383-94.

\section{Majid 2000}

Majid M, Cullum N, O'Meara S Sheldon T. Systematic reviews of wound care management: (4) diabetic foot ulceration. Health Technology Assessment 2000;21:113-238.

\section{Mason 1999}

Mason J, O'Keeffe C, McIntosh A, Hutchinson A, Booth A, Young RJ. A systematic review of foot ulcer in patients with type 2 diabetes mellitus. I: prevention. Diabetic Medicine 1999;16:801-12.

\section{Mayfield 1998}

Mayfield JA, Reiber GE, Sanders LJ, Janisse D, Pogach LM. Preventive foot care in people with diabetes. Diabetes Care 1998; 21:2161-77.

\section{Most 1983}

Most RS, Sinnock P. The epidemiology of lower extremity amputations in diabetic individuals. Diabetes Care 1983;6:87-91.

\section{Nabuurs-Franssen 2005}

Nabuurs-Franssen MH, Huijberts MS, Nieuwenhuijzen Kruseman AC, Willems J, Schaper NC. Health-related quality of life of diabetic foot ulcer patients and their caregivers. Diabetologia 2005 Sep;48(9):1906-10.

\section{Pecoraro 1990}

Pecoraro RE, Reiber GE, Burgess EM. Pathways to diabetic limb amputation. Basis for prevention. Diabetes Care 1990;13:513-21.

\section{Ragnarson Tennvall 2004}

Ragnarson Tennvall G, Apelqvist J. Health-economic consequences of diabetic foot lesions. Clinical Infectious Diseases 2004 Aug 1;39 (Suppl 2):S132-9.

\section{Reed 2005}

Reed D, Price EG, Windish DM, Wright SM, Gozu A, Hsu EB, et al.Challenges in systematic reviews of educational intervention 
studies. Annals of Internal Medicine 2005 Jun 21;142(12 Pt 2): 1080-9.

\section{Reenders 1993}

Reenders K, de Nobel E, van den Hoogen HJM, Rutten GEHM, van Weel C. Diabetes and its long-term complications in general practice: a survey in a well-defined population. Family Practice 1993;10:169-72.

\section{Rith-Najarian 2000}

Rith-Najarian SJ, Reiber GE. Prevention of foot problems in persons with diabetes. The Journal of Family Practice 2000 Nov;49 (11 Suppl):S30-9.

\section{Robbins 2008}

Robbins JM, Strauss G, Aron D, Long J, Kuba J, Kaplan Y. Mortality rates and diabetic foot ulcers: is it time to communicate mortality risk to patients with diabetic foot ulceration?. Journal of the American Podiatric Medical Association 2008 Nov-Dec;98(6): 489-93.

\section{Schellings 2005}

Schellings R, Kessels AG, Ter Riet G, Kleijnen J, Leffers P, Knottnerus JA, et al.Members of research ethics committees accepted a modification of the randomized consent design. Journal of Clinical Epidemiology 2005 Jun;58(6):589-94.

\section{Schultz 2010}

Schulz KF, Altman D, Moher D, for the CONSORT Group.

CONSORT 2010 Statement: Updated Guidelines for Reporting
ParallelGroup Randomized Trials. Annals of Internal Medicine 2010;152(11):1-7.

\section{SIGN 2009}

Scottish Intercollegiate Guidelines Network (SIGN). Search filters. http://www.sign.ac.uk/methodology/filters.html\#random (accessed 22 December 2009).

\section{Singh 2005}

Singh N, Armstrong DG, Lipsky BA. Preventing foot ulcers in patients with diabetes. JAMA 2005 Jan 12;293(2):217-28.

\section{St Vincent Declaration 1989}

World Health Organization (Europe) and International Diabetes Federation (Europe). Diabetes care and research in Europe: the Saint Vincent Declaration. Diabetic Medicine 1990 May;7(4):360.

\section{van Tulder 1997}

Tulder van MW, Assendelft WJJ, Koes BW, Bouter LM. Method guidelines for systematic reviews in the Cochrane Collaboration Back Review Group for Spinal Disorders. Spine 1997;22:2323-30.

\section{Vileikyte 2001}

Vileikyte L. Diabetic foot ulcers: a quality of life issue. Diabetes/ Metabolism Research and Reviews 2001 Jul-Aug;17(4):246-9.

\section{Wu 2007}

Wu SC, Driver VR, Wrobel JS, Armstrong DG. Foot ulcers in the diabetic patient, prevention and treatment. Vascular Health and Risk Management 2007;3(1):65-76.

* Indicates the major publication for the study 
CHARACTERISTICS OF STUDIES

Characteristics of included studies [ordered by study ID]

Barth 1991

\begin{tabular}{|c|c|}
\hline Methods & RCT \\
\hline Participants & $\begin{array}{l}70 \text { patients with type } 2 \text { diabetes mellitus - randomised (I: } 38 \text { vs C: } 32 \text { ) } \\
\text { Baseline risk for foot ulceration: PVD, I: } 19 \text { vs C: } 6 \text {. Number of foot problems: 'No } \\
\text { significant difference between groups'. } \\
\text { Baseline outcome measures: 'No significant difference between groups'. } \\
\text { Study setting: Secondary outpatient care, outpatient clinic in Australia. } \\
\text { Inclusion criteria: patients with type } 2 \text { diabetes mellitus }>3 \text { months and current treatment } \\
>1 \text { month, sub optimal glucose control, BMI not less than } 25 \text {, energy fat intake at least } \\
35 \% \text {, no education in previous six months, competence in English language }\end{array}$ \\
\hline Interventions & $\begin{array}{l}\text { Intervention group: } \\
\text { Normal patient education programme, consisting of fourteen hours group patient edu- } \\
\text { cation (over three consecutive days; groups of } 8 \text { to } 10 \text { people) including one hour lecture } \\
\text { and discussion by podiatrist. Content: standard diabetes education, one hour on foot } \\
\text { care and footwear. } \\
\text { Four weekly group patient education sessions of } 1.5 \text { to } 2.5 \text { hours (total nine hours), three } \\
\text { by podiatrist, one by psychologist on the base of cognitive motivation theory. Content: } \\
\text { recommendations and foot care education and demonstration and practicing foot care } \\
\text { procedures. } \\
\text { Control group: } \\
\text { Normal patient education programme, consisting of fourteen hours group patient edu- } \\
\text { cation (over three consecutive days; groups of } 8 \text { to } 10 \text { people) including one hour lecture } \\
\text { and discussion by podiatrist. Content: standard diabetes education, one hour on foot } \\
\text { care and footwear. } \\
\text { Adherence: not described. }\end{array}$ \\
\hline
\end{tabular}

Outcomes

Primary outcomes: not reported

Secondary outcomes: foot care knowledge, behaviour assessment score, foot problems requiring treatment.

Notes

Risk of bias

\begin{tabular}{lll}
\hline Item & Authors' judgement & Description \\
\hline Adequate sequence generation? & Unclear & No information provided. \\
\hline Allocation concealment? & Unclear & No information provided. \\
\hline $\begin{array}{l}\text { Blinding? } \\
\text { Blinding of outcome assessors }\end{array}$ & Yes & $\begin{array}{l}\text { Foot care knowledge and foot care routine compliance were as- } \\
\text { sessed with a questionnaire using multiple choice answers. Foot } \\
\text { problems were scored by an independent podiatrist, who was }\end{array}$ \\
\hline
\end{tabular}


Barth 1991 (Continued)

not aware of the patients' experimental conditions.

\begin{tabular}{|c|c|c|}
\hline $\begin{array}{l}\text { Incomplete outcome data addressed? } \\
\text { All outcomes }\end{array}$ & No & $\begin{array}{l}62 \text { of } 70 \text { patients completed six months follow-up (I: } 33 \text { vs C: } \\
\text { 29). Reasons for missing outcome data are described and are } \\
\text { unlikely to be related to the outcome. } \\
\text { No intention to treat analyses were undertaken. }\end{array}$ \\
\hline Free of selective reporting? & Yes & $\begin{array}{l}\text { No study protocol available, but the trial report lists the out- } \\
\text { comes of interest in both the methods and the results section. }\end{array}$ \\
\hline Free of other bias? & No & $\begin{array}{l}\text { Baseline risk for foot ulceration: PVD, I: } 19 \text { vs C: } 6(\mathrm{p}<0.05) \text {. } \\
\text { Number of foot problems: 'No significant difference between } \\
\text { groups'. } \\
\text { Co-interventions were not described. } \\
\text { Adherence to the intervention was not described. }\end{array}$ \\
\hline
\end{tabular}

Bloomgarden 1987

\begin{tabular}{|c|c|}
\hline Methods & RCT \\
\hline Participants & $\begin{array}{l}749 \text { insulin treated patients with diabetes mellitus randomised: } 345 \text { consented to par- } \\
\text { ticipate: } \\
\text { I: } 165 \text { vs C: } 180 \text {. } \\
\text { Baseline risk for foot ulceration: } \\
146 \text { patients had no foot lesion at initial evaluation, I: } 83 \text { vs C: } 63 \\
100 \text { patients had callus, nail dystrophy or fungal infection at initial evaluation, I: } 37 \text { vs } \\
\text { C: } 63 \\
20 \text { patients had an ulcer or amputation at initial evaluation, I: } 7 \text { vs C: } 13 \text {. } \\
\text { Study setting: primary care, diabetes clinic in the US. } \\
\text { Inclusion criteria: insulin treated diabetes mellitus (unclear which type of diabetes) }\end{array}$ \\
\hline Interventions & $\begin{array}{l}\text { Intervention group: } \\
\text { Nine group patient education sessions by nurse educator and nutritionist using film and } \\
\text { card games and individual instruction. Content: one group session of education on foot } \\
\text { care and skin hygiene, the other sessions on understanding diabetes, basic nutrition, } \\
\text { weight loss, food purchasing, meal planning, insulin administration, emergencies, risk } \\
\text { factors for macrovascular disease and individual diet instruction. } \\
\text { Control group: Usual care. Content: not specified. } \\
\text { Adherence: } 82(50 \%) \text { intervention group patients completed seven or more educational } \\
\text { group sessions. }\end{array}$ \\
\hline Outcomes & $\begin{array}{l}\text { Primary outcomes: ulcer or amputations } \\
\text { Secondary outcomes: callus, nail dystrophy or fungal infection, behaviour assessment } \\
\text { score }\end{array}$ \\
\hline Notes & $\begin{array}{l}\text { The reported outcome data on knowledge scores are not included in this review, because } \\
\text { the assessment tool only included questions about diabetes in general, but not on foot } \\
\text { care. }\end{array}$ \\
\hline
\end{tabular}


Bloomgarden 1987 (Continued)

\begin{tabular}{|c|c|c|}
\hline Item & Authors' judgement & Description \\
\hline Adequate sequence generation? & Unclear & No information provided. \\
\hline Allocation concealment? & Unclear & No information provided. \\
\hline $\begin{array}{l}\text { Blinding? } \\
\text { Blinding of outcome assessors }\end{array}$ & Unclear & No information provided. \\
\hline $\begin{array}{l}\text { Incomplete outcome data addressed? } \\
\text { All outcomes }\end{array}$ & No & $\begin{array}{l}266 \text { of } 345 \text { patients completed follow-up (I: } 127 \text { vs C: } 139 \text { ). } \\
\text { Reasons for missing outcome data are described and are unlikely } \\
\text { to be related to the outcome. Note: } 749 \text { patients were originally } \\
\text { randomised, but } 193 \text { did not attend the clinic during the period } \\
\text { of the study and } 211 \text { of those who did attend to the clinic de- } \\
\text { clined to participate, leaving only } 345 \text { study subjects. } \\
\text { No intention to treat analyses were undertaken. }\end{array}$ \\
\hline Free of selective reporting? & Unclear & $\begin{array}{l}\text { Unclear. No study protocol available. The outcomes ulcer and } \\
\text { amputation incidence, callus, nail dystrophy, fungal infection } \\
\text { and behaviour assessment score were not prespecified in the } \\
\text { methods section of the study report, but this is more likely to } \\
\text { be a result of insufficient rather than selective reporting. }\end{array}$ \\
\hline Free of other bias? & No & $\begin{array}{l}\text { Baseline risk for foot ulceration: } \\
146 \text { patients had no foot lesion at initial evaluation, I: } 83 \text { vs C: } \\
63 \\
100 \text { patients had callus, nail dystrophy or fungal infection at } \\
\text { initial evaluation, I: } 37 \text { vs C: } 63 \\
20 \text { patients had an ulcer or amputation at initial evaluation, I: } \\
7 \text { vs C: } 13 \text {. } \\
\text { Co-interventions were not described. } \\
\text { Adherence: } 82(50 \%) \text { intervention group patients completed } \\
\text { seven or more educational group sessions. }\end{array}$ \\
\hline
\end{tabular}

\section{Borges 2004}

\begin{tabular}{ll}
\hline Methods & RCT \\
\hline Participants & $\begin{array}{l}\text { 167 type } 2 \text { diabetes patients randomised: I: 55. Only risk assessment (RA): } 55 . \text { C: } 57 . \\
\text { Baseline risk for foot ulceration: no data provided. } \\
\text { Baseline outcome measures: patients' behaviour assessment scores: I: 4.7. RA: 4.8. C: } 5.1 . \\
\text { Foot care knowledge scores: no significant differences. Self efficacy scores: no significant } \\
\text { differences. } \\
\text { Study setting: two community hospital emergency departments near the USA.-Mexico } \\
\text { border }\end{array}$
\end{tabular}




\begin{tabular}{|c|c|c|}
\hline & \multicolumn{2}{|c|}{$\begin{array}{l}\text { Inclusion criteria: patients with type } 2 \text { diabetes, age } 40 \text { years or older, residing within } \\
\text { the country, presenting at the ED with non emergent health problems, not having active } \\
\text { foot ulceration or other foot pathology, able to communicate verbally, agreeing on a } \\
\text { home visit. }\end{array}$} \\
\hline Interventions & \multicolumn{2}{|c|}{$\begin{array}{l}\text { Intervention group: } \\
\text { Lower extremity amputation risk assessment. Content: use of a monofilament. } \\
15 \text { minute foot self-care education session by the researcher. Content: information about } \\
\text { the patients risk assessment score, recommendations for foot self-care based on the } \\
\text { individual risk score, a discussion about the barriers to optimal self-care and an outline } \\
\text { of the importance of daily foot self-care. } \\
\text { Risk assessment group: Lower extremity amputation risk assessment. Content: use of a } \\
\text { monofilament. } \\
\text { Control group: No intervention } \\
\text { Adherence: no data provided, but likely that all intervention group patients received the } \\
\text { single brief educational session directly after randomisation. }\end{array}$} \\
\hline Outcomes & \multicolumn{2}{|c|}{$\begin{array}{l}\text { Primary outcomes: not reported } \\
\text { Secondary outcomes: foot care knowledge scores, patients' behaviour assessment scores } \\
\text { (self-reported and observed) }\end{array}$} \\
\hline \multicolumn{3}{|l|}{ Notes } \\
\hline \multicolumn{3}{|l|}{ Risk of bias } \\
\hline Item & Authors' judgement & Description \\
\hline Adequate sequence generation? & Unclear & No information provided. \\
\hline Allocation concealment? & Unclear & No information provided. \\
\hline $\begin{array}{l}\text { Blinding? } \\
\text { Blinding of outcome assessors }\end{array}$ & Yes & $\begin{array}{l}\text { The research assistant, who was the outcome assessor, was } \\
\text { masked to group assignment. }\end{array}$ \\
\hline $\begin{array}{l}\text { Incomplete outcome data addressed? } \\
\text { All outcomes }\end{array}$ & No & $\begin{array}{l}141 \text { of } 167 \text { patients completed one month follow-up (I: } 47 . \text { RA: } \\
\text { 48. C: } 46 \text { ). Drop-out is balanced in numbers across intervention } \\
\text { groups, but reasons for missing data were not reported. } \\
\text { No intention to treat analyses were undertaken. }\end{array}$ \\
\hline Free of selective reporting? & Yes & $\begin{array}{l}\text { No study protocol available, but the trial report lists the out- } \\
\text { comes of interest in both the methods and the results section. }\end{array}$ \\
\hline Free of other bias? & Unclear & $\begin{array}{l}\text { Baseline risk for foot ulceration: no data provided. } \\
\text { There were no co-interventions } \\
\text { Adherence: no data provided, but likely that all intervention } \\
\text { group patients received the single brief educational session di- } \\
\text { rectly after randomisation. }\end{array}$ \\
\hline
\end{tabular}




\begin{tabular}{|c|c|c|}
\hline Methods & \multicolumn{2}{|l|}{ RCT } \\
\hline Participants & \multicolumn{2}{|c|}{$\begin{array}{l}40 \text { patients with type } 2 \text { diabetes mellitus randomised: I: } 20 \text { vs C: } 20 \text {. } \\
\text { Baseline risk for foot ulceration: } \\
70 \% \text { had loss of protective sensation. } \\
67 \% \text { had impaired lower extremity circulation. } \\
50 \% \text { had a foot deformity. } \\
\text { Foot risk assessment: no significant differences between groups. } \\
\text { Baseline outcome measures: no significant differences between groups. } \\
\text { Study setting: community-based care, patients with type } 2 \text { diabetes mellitus admitted to } \\
\text { home care in the USA. } \\
\text { Inclusion criteria: physically and mentally able to participate, able to read and understand } \\
\text { English, age } 18 \text { years or older, no lower-extremity ulcer, no history of lower-extremity } \\
\text { amputation }\end{array}$} \\
\hline Interventions & \multicolumn{2}{|c|}{$\begin{array}{l}\text { Intervention group: } \\
10-20 \text { minutes individualised patient education including verbal and written instructions } \\
\text { according to participants' risk factors and foot care knowledge, self-efficacy and reported } \\
\text { self care behaviour by research nurse. Content: foot care education topics: individual risk } \\
\text { factors, washing and drying feet, toenail care, footwear, moisturising feet, reportable foot } \\
\text { problems. If desired: demonstration of nail trimming and problem-solving discussion to } \\
\text { discover alternative care solutions } \\
\text { Control group: No intervention } \\
\text { Adherence: } 19 \text { of } 20 \text { intervention group patients attended the single education session. }\end{array}$} \\
\hline Outcomes & \multicolumn{2}{|c|}{$\begin{array}{l}\text { Primary outcomes: not reported } \\
\text { Secondary outcomes: foot care knowledge score, foot care practice score, patients' self } \\
\text { confidence scores. }\end{array}$} \\
\hline \multicolumn{3}{|l|}{ Notes } \\
\hline \multicolumn{3}{|l|}{ Risk of bias } \\
\hline Item & Authors' judgement & Description \\
\hline Adequate sequence generation? & Yes & $\begin{array}{l}\text { Randomly drawing labelled consent forms, the sequence having } \\
\text { been generated by shuffling. }\end{array}$ \\
\hline Allocation concealment? & Yes & $\begin{array}{l}\text { Consent form labels were covered by opaque stickers and ran- } \\
\text { domly shuffled. }\end{array}$ \\
\hline $\begin{array}{l}\text { Blinding? } \\
\text { Blinding of outcome assessors }\end{array}$ & Unclear & No information provided. \\
\hline $\begin{array}{l}\text { Incomplete outcome data addressed? } \\
\text { All outcomes }\end{array}$ & No & $\begin{array}{l}35 \text { of } 40 \text { patients completed follow-up (I: } 19 \text { vs C: } 16 \text { ). Reasons } \\
\text { for missing data were not reported. } \\
\text { No intention to treat analyses were undertaken. }\end{array}$ \\
\hline
\end{tabular}


Corbett 2003 (Continued)

\begin{tabular}{|c|c|c|}
\hline Free of selective reporting? & Yes & $\begin{array}{l}\text { No study protocol available, but the trial report lists the out- } \\
\text { comes of interest in both the methods and the results section. }\end{array}$ \\
\hline Free of other bias? & Unclear & $\begin{array}{l}\text { Baseline foot risk assessment: 'no significant differences between } \\
\text { groups'. } \\
\text { Co-interventions were not described. } \\
\text { Adherence: } 19 \text { of } 20 \text { intervention group patients attended the } \\
\text { single education session. }\end{array}$ \\
\hline
\end{tabular}

Frank 2003

\begin{tabular}{|c|c|}
\hline Methods & RCT \\
\hline Participants & 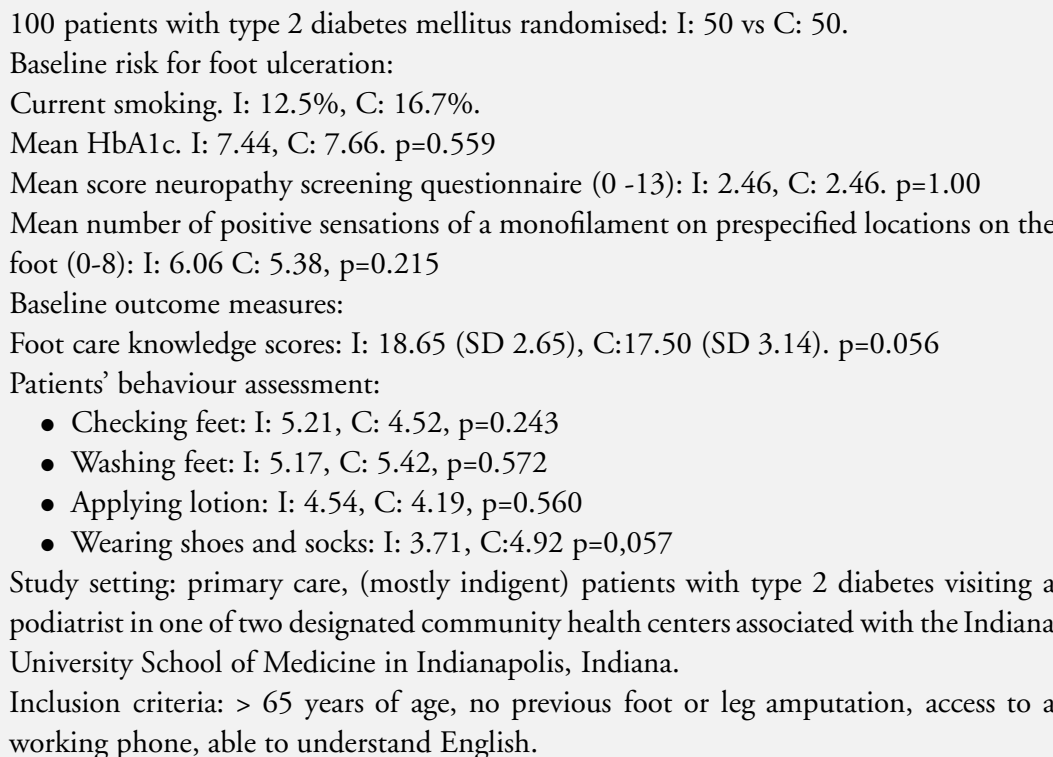 \\
\hline Interventions & $\begin{array}{l}\text { Intervention group: } \\
\text { Lower extremity amputation risk assessment. Content: use of a monofilament. } \\
\text { Foot care videotape. Content: people demonstrating proper foot care. } \\
\text { Bag of foot supplies. Content: soap, towel, socks, mirror, toenail clippers, lotion samples, } \\
\text { information on smoking cessation and exercise. } \\
\text { Handout. Content: foot care instructions. } \\
30-40 \text { minute individualised education session by research nurse. Content: persuasion } \\
\text { to perform foot care + demonstration of content of bag of foot supplies. } \\
\text { Reminder checklist. Content: instructions for daily foot care. } \\
\text { Weekly reminder telephone calls. Content: persuasion to perform foot care. } \\
\text { Care as usual by a podiatrist. } \\
\text { Control group: } \\
\text { Lower extremity amputation risk assessment. Content: use of a monofilament. } \\
\text { Weekly telephone calls. Content: only outcome assessment. } \\
\text { Care as usual by a podiatrist. }\end{array}$ \\
\hline
\end{tabular}


Frank 2003 (Continued)

Adherence: no data provided, but likely that all intervention group patients received the single brief educational session directly after randomisation.

\begin{tabular}{l|l} 
Outcomes & $\begin{array}{l}\text { Primary outcomes: not reported } \\
\text { Secondary outcomes: foot care knowledge scores, patients' self-reported foot care be- } \\
\text { haviour scores. }\end{array}$ \\
\hline Notes & $\begin{array}{l}\text { It was originally intended to report changes in 'weekly trimming of toenails', but this } \\
\text { was abandoned, as all patients were seen by a podiatrist for trimming of their toenails. }\end{array}$
\end{tabular}

Risk of bias

\begin{tabular}{|c|c|c|}
\hline Item & Authors' judgement & Description \\
\hline Adequate sequence generation? & Yes & $\begin{array}{l}\text { Papers with either 'group A' or 'group B' were drawn from an } \\
\text { envelope. }\end{array}$ \\
\hline Allocation concealment? & No & The envelope was not sealed. \\
\hline $\begin{array}{l}\text { Blinding? } \\
\text { Blinding of outcome assessors }\end{array}$ & No & $\begin{array}{l}\text { Outcomes were assessed by the research nurse, who also per- } \\
\text { formed the educational intervention. }\end{array}$ \\
\hline $\begin{array}{l}\text { Incomplete outcome data addressed? } \\
\text { All outcomes }\end{array}$ & No & $\begin{array}{l}96 \text { of } 100 \text { patients completed four weeks follow-up (I: } 48 \text { vs C: } \\
48 \text { ). } \\
\text { No intention to treat analyses were undertaken. }\end{array}$ \\
\hline Free of selective reporting? & Yes & $\begin{array}{l}\text { No study protocol available, but the trial report lists the out- } \\
\text { comes of interest in both the methods and the results section. }\end{array}$ \\
\hline Free of other bias? & Unclear & $\begin{array}{l}\text { Baseline risk for foot ulceration: } \\
\text { Current smoking. I: } 12.5 \%, \text { C: } 16.7 \% \text {. } \\
\text { Mean HbAlc: I 7.44, C: } 7.66, p=0.559 \\
\text { Mean score neuropathy screening questionnaire }(0-13) \text { : I: } 2.46 \text {, } \\
\text { C: } 2.46, p=1.00 \\
\text { Mean number of positive sensations of a monofilament on pre- } \\
\text { specified locations on the foot (0-8): I: } 6.06, \text { C: } 5.38, p=0.215 \\
\text { Co-interventions were not described. } \\
\text { Adherence: no data provided, but likely that all intervention } \\
\text { group patients received the single brief educational session di- } \\
\text { rectly after randomisation. }\end{array}$ \\
\hline
\end{tabular}

\section{Kruger 1992}

\begin{tabular}{ll}
\hline Methods & RCT \\
\hline Participants & 50 patients with diabetes mellitus randomised: \\
& I: $23 ;$ C: 27 \\
& Baseline risk for foot ulceration: no data provided.
\end{tabular}


Kruger 1992 (Continued)

Study setting: Secondary outpatient care in the USA.

Inclusion criteria: diabetes duration at least five years (unclear which type of diabetes), no frank pathology, entering weekly hospital diabetes program

$\begin{array}{ll}\text { Interventions } & \text { Intervention group: } \\ \text { One week patient education session. Content: education and guidance (unclear by } \\ \text { whom) to assist patients in achieving higher levels of general diabetes control. } \\ \text { Instructional videotape with supplementary explanation from an instructor. Content: } \\ \text { usual teaching on foot care. } \\ \text { Additional hands-on learning sessions during the same week. Content: actual foot wash- } \\ \text { ing, inspection, assessment, demonstration of care of corns and callus, toenail cutting, } \\ \text { identification of potential foot problems, evaluation foot care. } \\ \text { Patient education kit. Content: buff pads and mirror. } \\ \text { Daily foot check sheets. Content: encouragement to perform daily foot inspection. } \\ \text { Control group: } \\ \text { One week patient education session. Content: education and guidance (unclear by } \\ \text { whom) to assist patients in achieving higher levels of general diabetes control. } \\ \text { Instructional videotape with supplementary explanation from an instructor. Content: } \\ \text { usual teaching on foot care. } \\ \text { Daily foot check sheets. Content: encouragement to daily foot inspection. } \\ \text { Adherence: no data provided. } \\ \end{array}$

Outcomes Primary outcomes: none reported

Secondary outcomes: foot status, foot care knowledge scores, behaviour assessment.

Notes

Risk of bias

\begin{tabular}{|c|c|c|}
\hline Item & Authors' judgement & Description \\
\hline Adequate sequence generation? & No & $\begin{array}{l}\text { Patients were allocated to the experimental or control interven- } \\
\text { tion on the basis of the week that they entered the diabetes pro- } \\
\text { gram. The experimental group was developed similarly from the } \\
\text { control group on alternate weeks. } \\
\text { Quote: "A random selection process determined whether the } \\
\text { control or the experimental group would begin the study". }\end{array}$ \\
\hline Allocation concealment? & No & $\begin{array}{l}\text { Alternation is not an adequate method of allocation conceal- } \\
\text { ment. }\end{array}$ \\
\hline $\begin{array}{l}\text { Blinding? } \\
\text { Blinding of outcome assessors }\end{array}$ & Unclear & No information provided. \\
\hline $\begin{array}{l}\text { Incomplete outcome data addressed? } \\
\text { All outcomes }\end{array}$ & No & $\begin{array}{l}30 \text { of } 50 \text { patients completed six months follow-up (I: } 15 ; \mathrm{C}: 15 \text { ) } \\
\text { Reasons for dropping-out were death (two), not wanting to } \\
\text { make an appointment at the scheduled time and moving without } \\
\text { leaving a forwarding address. } \\
\text { No intention to treat analyses were undertaken. }\end{array}$ \\
\hline
\end{tabular}




\section{Kruger 1992 (Continued)}

\begin{tabular}{|c|c|c|}
\hline Free of selective reporting? & Yes & $\begin{array}{l}\text { Yes. No study protocol available, but the trial report lists the } \\
\text { outcomes of interest in both the methods and the results section. }\end{array}$ \\
\hline Free of other bias? & Unclear & $\begin{array}{l}\text { Baseline risk for foot ulceration: no data provided. } \\
\text { Co-interventions were not described. } \\
\text { Adherence: no data provided. }\end{array}$ \\
\hline
\end{tabular}

Lincoln 2008

\begin{tabular}{|c|c|}
\hline Methods & RCT \\
\hline Participants & $\begin{array}{l}178 \text { patients with diabetes and a newly healed foot ulcer randomised. I: } 87, \text { C: } 85 \text {. } \\
\text { Excluded after randomisation: six } \\
\text { Baseline risk for foot ulceration: } \\
\text { Loss of } 10 \mathrm{~g} \text { monofilament stimulus perception: I: } 47 \% \text {, C: } 42 \% \text {. } \\
\text { Loss of neuro tip perception: I: } 35 \% \text {, C: } 36 \% \text {. } \\
\text { Loss of vibration perception: I: } 68 \% \text {, C: } 62 \% \text {. } \\
\text { Absent foot pulses: I: } 20 \% \text {, C: } 28 \% \text {. } \\
\text { Baseline outcome measures: } \\
\text { History of foot ulcer: all participants. } \\
\text { Site of previous foot ulcer: Fore foot: I: } 81 \% \text {, C: } 80 \% \text {. Mid and hindfoot: I: } 19 \% \text {, C: } \\
20 \% \text {. } \\
\text { Amputation rate: Previous amputation same leg: I: } 20 \% \text {, C: } 12 \% \text {. Previous amputation } \\
\text { other leg: I: } 7 \% \text { minor, } 3 \% \text { major. C: } 6 \% \text { minor, } 3 \% \text { major. } \\
\text { No baseline behaviour assessment scores provided. } \\
\text { Study setting: Secondary outpatient care: specialist foot clinic in Nottingham, UK. } \\
\text { Inclusion criteria: patients with newly healed diabetic foot ulcers (ulcer free for } 28 \text { days } \\
\text { or more), not living in institutions, no history of dementia, no serious medical problems, } \\
\text { English speaking or having an English speaking caregiver, living < } 50 \text { miles from the } \\
\text { clinic, not included in any other study. }\end{array}$ \\
\hline
\end{tabular}

Interventions

Intervention group:

Single one hour structured foot care education session by one of the researchers during a home visit. Content: explanation of the principal causes of foot ulcers, illustrations of foot lesions, advises on avoiding accidental damage, identification personal risk factors, evaluation of footwear.

Hand-outs. Content: information about the causes of foot ulcers, foot care and ways to reduce the likelihood of accidents.

Telephone call four weeks after the education session. Content: assessment of the need for clarification and reinforcement of the educational session content.

Control group: Hand-outs. Content: information about the causes of foot ulcers, foot care and ways to reduce the likelihood of accidents.

Adherence: no data provided, but likely that all intervention group patients received the one hour at home education session.

Outcomes

Primary outcomes: ulcer incidence (recurrence), amputation rate Secondary outcomes: patients' behaviour assessment scores 
Lincoln 2008 (Continued)

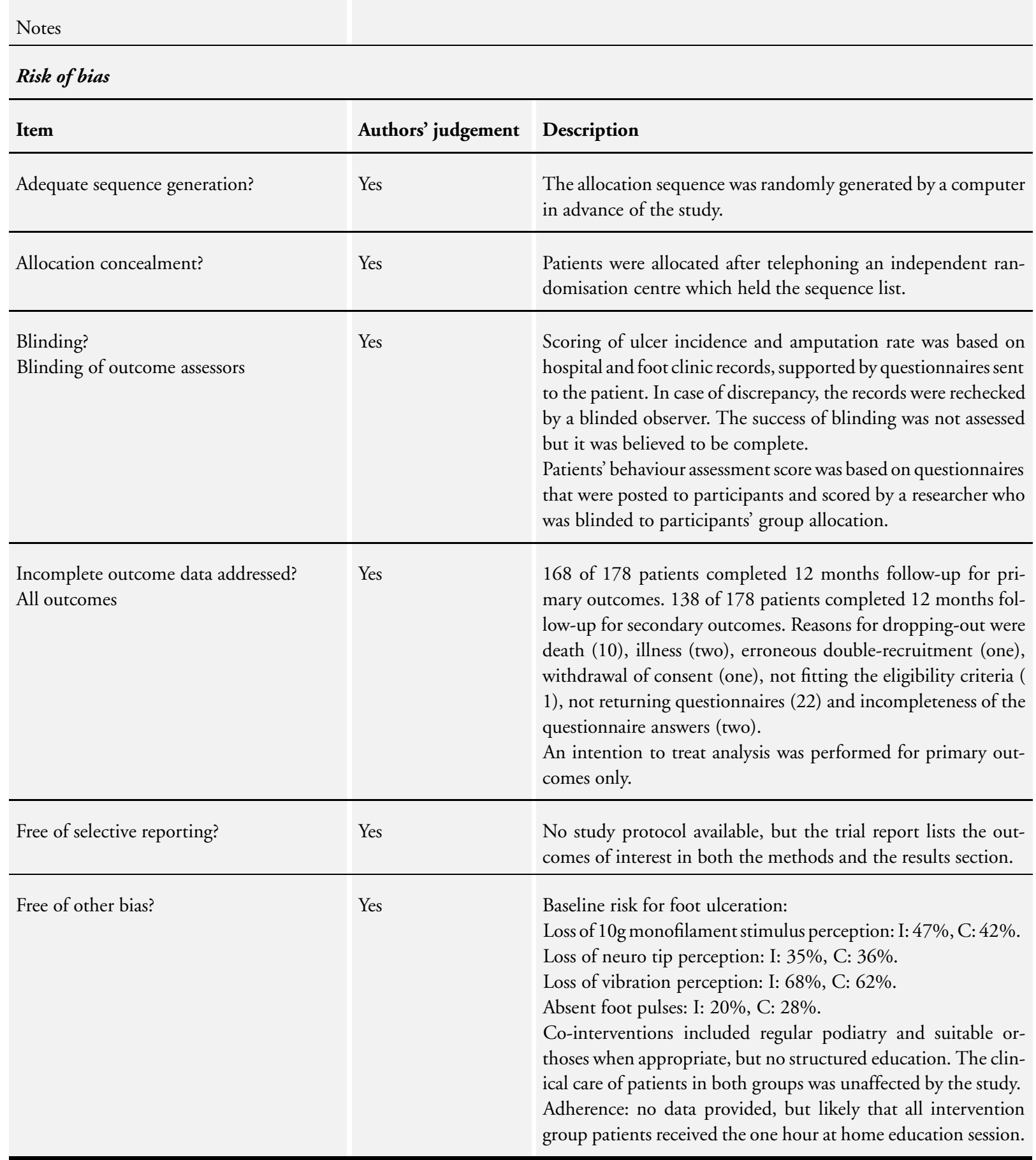




\begin{tabular}{ll}
\hline Methods & RCT \\
\hline Participants & $\begin{array}{l}227 \text { patients with diabetes mellitus and foot infection, ulceration or prior amputation - } \\
\text { randomised. } 203 \text { patients included: I: } 103 \text {; C: } 100 .\end{array}$ \\
Baseline risk for foot ulceration: although described as 'not significant', prior vascular \\
reconstruction higher in C and incidence of foot callus higher in I ( $<<0.05)$. No signif- \\
icant differences in foot deformities, neuropathy, gangrene, prior amputation or ulcer \\
and level of distal pulses. \\
$\begin{array}{l}\text { Study setting: Secondary outpatient care, podiatric or vascular surgery care in the USA. } \\
\text { Inclusion criteria: patients with diabetes (unclear which type) with foot infection, ulcer- } \\
\text { ation or prior amputation referred for podiatry or vascular surgery }\end{array}$ \\
\hline
\end{tabular}

Interventions

Outcomes
Intervention group:

One hour group patient education with slides given by podiatrist and set of patient instructions. Content: slides of infected diabetic feet and amputated diabetic limbs, simple set of patient instructions for diabetic foot care.

Routine patient education. Content: routine diabetic teaching on diet, weight, exercise and medication.

Control group: Routine patient education. Content: routine diabetic teaching on diet, weight, exercise and medication.

Adherence: no data provided.

Primary outcomes: ulcer incidence, incidence of infections, amputation rate

Secondary outcomes: none

Notes

Unit of randomisation: individual patients. Unit of analyses: separate limbs.

\section{Risk of bias}

\begin{tabular}{l|l|l}
\hline Item & Authors' judgement & Description \\
\hline Adequate sequence generation? & No & $\begin{array}{l}\text { Quote: "Patients were randomised into two groups based upon } \\
\text { the odd or even last digit of their Social Security number". }\end{array}$ \\
\hline $\begin{array}{l}\text { Allocation concealment? } \\
\text { Blinding? }\end{array}$ & No & $\begin{array}{l}\text { Sequence generation was based upon the last digit of the patients' } \\
\text { social security number. }\end{array}$ \\
\hline $\begin{array}{l}\text { Blinding of outcome assessors } \\
\text { Incomplete outcome data addressed? }\end{array}$ & No & No information provided. \\
\hline $\begin{array}{l}\text { All outcomes } \\
\text { Nree of selective reporting? }\end{array}$ & $\begin{array}{l}182 \text { of 227 patients completed follow-up (I: 90; C: 92). Reasons } \\
\text { for dropping-out were: not fitting the eligibility criteria (24), } \\
\text { death (13) and unspecified (eight). } \\
\text { No intention to treat analyses were undertaken. }\end{array}$ \\
\hline Yes & $\begin{array}{l}\text { No study protocol available, but the trial report lists the out- } \\
\text { comes of interest in both the methods and the results section. }\end{array}$
\end{tabular}


Malone 1989 (Continued)

\begin{tabular}{|l|l|}
\hline Free of other bias? & $\begin{array}{l}\text { Baseline risk for foot ulceration: although described as 'not sig- } \\
\text { nificant', prior vascular reconstruction higher in Cand incidence } \\
\text { of foot callus higher in I }(\mathrm{p}<0.05) \text {. No significant differences } \\
\text { in foot deformities, neuropathy, gangrene, prior amputation or } \\
\text { ulcer and level of distal pulses. }\end{array}$ \\
& $\begin{array}{l}\text { Co-interventions were not described. } \\
\text { Adherence: no data provided. }\end{array}$ \\
\hline
\end{tabular}

Mazzuca 1986

\begin{tabular}{ll}
\hline Methods & RCT \\
\hline Participants & $\begin{array}{l}532 \text { patients with diabetes mellitus randomised I: 263; C: } 269 . \\
\text { Baseline risk for foot ulceration: no data provided. } \\
\text { Study setting: Primary care, academic general medicine clinic in the USA } \\
\text { Inclusion criteria: Either two fasting blood glucose }>130 \mathrm{mg} / \mathrm{dl} \text { or one }>150 \mathrm{mg} / \mathrm{dl} \text { or } \\
\text { two hour value }>250 \mathrm{mg} / \mathrm{dl} \text {, able to perform two basic self care tasks, no psychiatric or } \\
\text { terminal illness, under care of an internal medicine resident, informed consent }\end{array}$ \\
\hline Interventions & $\begin{array}{l}\text { Intervention group: } \\
\text { Diagnosis of educational needs according to protocol. } \\
\text { Patient education in appropriate modules of instruction by nurses and dieticians by } \\
\text { group education using lecture, discussion and/or audio-visual materials, demonstration, } \\
\text { return demonstration and feedback, goal setting, and written contract on goals. Content } \\
\text { (depending on individual educational needs): understanding diabetes, acute complica- } \\
\text { tions, antidiabetic medication, antihypertensive medication, diet and activity, foot care } \\
\text { and urine testing. } \\
\text { Reinforcement by phone contact two and six weeks after instruction. } \\
\text { Control group: Usual care. Content: including routine education. } \\
\text { Adherence: } 139 \text { of } 208 \text { (67\%) patients needing instruction on foot care completed this. }\end{array}$ \\
\hline Notes & $\begin{array}{l}\text { Primary outcomes: none reported } \\
\text { Secondary outcomes: level of foot care knowledge }\end{array}$ \\
\hline Kutcomes & \begin{tabular}{l} 
Knowledge objectives unclear \\
\hline
\end{tabular} \\
\hline
\end{tabular}

Risk of bias

\begin{tabular}{lll}
\hline Item & Authors' judgement & Description \\
\hline Adequate sequence generation? & Unclear & No information provided. \\
\hline Allocation concealment? & Unclear & No information provided. \\
\hline $\begin{array}{l}\text { Blinding? } \\
\text { Blinding of outcome assessors }\end{array}$ & No & $\begin{array}{l}\text { Assessments were not conducted by personnel who were blind } \\
\text { to subjects' experimental condition. }\end{array}$
\end{tabular}


Mazzuca 1986 (Continued)

\begin{tabular}{l|l|l}
\hline $\begin{array}{l}\text { Incomplete outcome data addressed? } \\
\text { All outcomes }\end{array}$ & No & $\begin{array}{l}275 \text { of } 532 \text { patients completed follow-up (I: 135; C: 140). Rea- } \\
\text { sons for dropping-out were death (30), physical or psychologi- } \\
\text { cal incapacitation (43), transfer to a senior staff physician (32), } \\
\text { relocation (13), work conflict (24), personal reasons (45), failure } \\
\text { to keep appointments (11) and lost contact (58). } \\
\text { No intention to treat analyses were undertaken. }\end{array}$ \\
\hline Free of selective reporting? & Yes & $\begin{array}{l}\text { No study protocol available, but the trial report lists the out- } \\
\text { comes of interest in both the methods and the results section. }\end{array}$ \\
\hline Free of other bias? & No & $\begin{array}{l}\text { Baseline risk for foot ulceration: no data provided. } \\
\text { Co-interventions were not described. } \\
\text { Adherence: } 139 \text { of } 208 \text { (67\%) patients needing instruction on } \\
\text { foot care completed this. }\end{array}$ \\
\hline
\end{tabular}

\section{Rettig 1986}

\begin{tabular}{|c|c|c|}
\hline Methods & \multicolumn{2}{|l|}{ RCT } \\
\hline Participants & \multicolumn{2}{|c|}{$\begin{array}{l}471 \text { patients with diabetes mellitus randomised I: 228; C: } 243 \text {. } \\
\text { Baseline risk for foot ulceration: no data provided. } \\
\text { Study setting: Community-based care } \\
\text { Inclusion criteria: identified as diabetic inpatient of participating hospitals (unclear which } \\
\text { type of diabetes), age < } 65 \text { years (at begin of study), no terminal illness, physician approval }\end{array}$} \\
\hline Interventions & \multicolumn{2}{|c|}{$\begin{array}{l}\text { Intervention group: } \\
\text { Up to } 12 \text { home patient education sessions, provided by nurses, who attended special } \\
\text { four day intensive course in diabetes self care. Content: according to judgement of nurse, } \\
\text { tailored to patient self management needs, which were defined with } 100 \text { short answer } \\
\text { and yes/no questions. } \\
\text { Control group: Usual care. Content: not specified. } \\
\text { Adherence: no data provided. }\end{array}$} \\
\hline Outcomes & \multicolumn{2}{|c|}{$\begin{array}{l}\text { Primary outcomes: none } \\
\text { Secondary outcomes: foot appearance score, foot care knowledge, behaviour assessment } \\
\text { score }\end{array}$} \\
\hline \multicolumn{3}{|l|}{ Notes } \\
\hline \multicolumn{3}{|l|}{ Risk of bias } \\
\hline Item & Authors' judgement & Description \\
\hline Adequate sequence generation? & Unclear & No information provided. \\
\hline Allocation concealment? & Unclear & No information provided. \\
\hline
\end{tabular}


Rettig 1986 (Continued)

\begin{tabular}{l|l|l}
\hline $\begin{array}{l}\text { Blinding? } \\
\text { Blinding of outcome assessors }\end{array}$ & Yes & $\begin{array}{l}\text { The staff nurses, who were the outcome assessors, were not aware } \\
\text { of subject assignment at the time of the follow-up visit. }\end{array}$ \\
\hline $\begin{array}{l}\text { Incomplete outcome data addressed? } \\
\text { All outcomes }\end{array}$ & No & $\begin{array}{l}373 \text { of } 471 \text { patients completed follow-up (I: 180; C: 193). Rea- } \\
\text { sons for dropping-out were deaths, violations of the protocol ( } \\
\text { such as an excessive number of home visits) and unspecified. } \\
\text { No intention to treat analyses were undertaken. }\end{array}$ \\
\hline Free of selective reporting? & Yes & $\begin{array}{l}\text { No study protocol available, but the trial report lists the out- } \\
\text { comes of interest in both the methods and the results section. }\end{array}$ \\
\hline Free of other bias? & Unclear & $\begin{array}{l}\text { Baseline risk for foot ulceration: no data provided. } \\
\text { Co-interventions were not described. } \\
\text { Adherence: no data provided. }\end{array}$ \\
\hline
\end{tabular}

Rönnemaa 1997

\begin{tabular}{|c|c|}
\hline Methods & RCT \\
\hline Participants & $\begin{array}{l}530 \text { patients with diabetes mellitus randomised } \\
\text { I: } 267 \text { vs C: } 263 \\
\text { Baseline risk for foot ulceration: no data provided } \\
\text { Baseline outcome measures: } \\
\text { Foot care knowledge score: I } 26.7 \text { (SD 11.4); C } 26.1 \text { (SD 11.8) } \\
\text { Self care behaviour assessment score: I 5.4 (SD 2.8); C } 5.3 \text { (SD 2.6) } \\
\text { Callosities: I } 18,5 \% \text { calcaneal region, } 54.5 \% \text { other regions. C } 16.8 \% \text { calcaneal region, } \\
51.3 \% \text { other regions. } \\
\text { Diameter of greatest callosity: } \\
\text { I calcaneal region ( } \mathrm{n}=49) 40.5 \mathrm{~mm} \text { (SD } 30.8 \text { ), other regions ( } \mathrm{n}=141) 16.6 \mathrm{~mm} \text { (SD } \\
10.2 \text { ). } \\
\text { C calcaneal region ( } \mathrm{n}=55 \text { ) } 30.6 \mathrm{~mm} \text { (SD 28.5), other regions ( } \mathrm{n}=138 \text { ) } 15.2 \mathrm{~mm} \text { (SD } \\
9.8 \text { ). } \\
\text { Podiatrist visit: I } 12.4 \% \text { in previous year, } 73.4 \% \text { never before. C } 10.4 \% \text { in previous year, } \\
76.1 \% \text { never before. } \\
\text { Foot examination by physician in previous year: I } 36.7 \% \text { routinely, } 9.5 \% \text { following } \\
\text { complaints. C } 46.4 \% \text { routinely, } 12.3 \% \text { following complaints. } \\
\text { Study setting: Community-based care in the vicinity of Turku, Finland. } \\
\text { Inclusion criteria: included in the national drug imbursement register for receiving an- } \\
\text { tidiabetic treatment, no obvious need for podiatry, no visit with podiatrist in previous } 6 \\
\text { months, age between } 10 \text { to } 79 \text { years }\end{array}$ \\
\hline Interventions & $\begin{array}{l}\text { Intervention group: } \\
45 \text { minutes individual patient education. Content: education on use of proper footwear, } \\
\text { daily hygiene, cutting of toenails, use of emollient cream, avoidance of high risk situations } \\
\text { and foot gymnastics. } \\
\text { Podiatric care visits (to one of three participating podiatrists) of } 30 \text { to } 60 \text { minutes duration } \\
\text { as necessary. Content: preventative podiatric care as debridement of callus, preparation }\end{array}$ \\
\hline
\end{tabular}


Rönnemaa 1997 (Continued)

\begin{tabular}{|c|c|c|}
\hline & \multicolumn{2}{|c|}{$\begin{array}{l}\text { of insoles, treatment of ingrowing toenails, guidance for foot gymnastics. } \\
\text { Control group: Written information. Content: instructions on foot care. } \\
\text { Adherence: I: mean number of podiatry visits } 4.7 \text { in first year. After first and before } \\
\text { seventh follow-up year at least one podiatry visit in } 82.3 \% \text { of patients in I and in } 49.7 \% \\
\text { in C. }\end{array}$} \\
\hline Outcomes & \multicolumn{2}{|c|}{$\begin{array}{l}\text { Primary outcomes: amputation rate, ulcer incidence } \\
\text { Secondary outcomes: callus development, foot care knowledge, behaviour assessment } \\
\text { scores }\end{array}$} \\
\hline \multicolumn{3}{|l|}{ Notes } \\
\hline \multicolumn{3}{|l|}{ Risk of bias } \\
\hline Item & Authors' judgement & Description \\
\hline Adequate sequence generation? & Unclear & $\begin{array}{l}\text { Randomisation was performed separately for men and women } \\
\text { and for patients below and above } 20 \text { years of age. Method of } \\
\text { randomisation not described. }\end{array}$ \\
\hline Allocation concealment? & Unclear & No information provided. \\
\hline $\begin{array}{l}\text { Blinding? } \\
\text { Blinding of outcome assessors }\end{array}$ & Unclear & $\begin{array}{l}\text { The outcome assessor was blinded to the baseline characteristics, } \\
\text { but no further information on blinding to the group allocation } \\
\text { is provided. }\end{array}$ \\
\hline $\begin{array}{l}\text { Incomplete outcome data addressed? } \\
\text { All outcomes }\end{array}$ & No & $\begin{array}{l}\text { Follow-up was completed by only } 63 \% \text { of patients in the inter- } \\
\text { vention group and } 62 \% \text { of patients in the control group at seven } \\
\text { years. } \\
\text { No intention to treat analysis undertaken. }\end{array}$ \\
\hline Free of selective reporting? & Yes & $\begin{array}{l}\text { No study protocol available, but the trial report lists the out- } \\
\text { comes of interest in both the methods and the results section. }\end{array}$ \\
\hline Free of other bias? & No & $\begin{array}{l}\text { Baseline risk for foot ulceration: no data provided. } \\
\text { Adherence: I: mean number of podiatry visits } 4.7 \text { in first year. } \\
\text { After first and before seventh follow-up year at least one podiatry } \\
\text { visit in } 82.3 \% \text { of patients in I and in } 49.7 \% \text { in C. } \\
\text { Co-interventions: podiatry care was provided to intervention } \\
\text { group patients only. }\end{array}$ \\
\hline
\end{tabular}


Characteristics of excluded studies [ordered by study ID]

\begin{tabular}{|c|c|}
\hline Dargis 1999 & Not a randomised controlled study design. \\
\hline Davidson 2000 & $\begin{array}{l}\text { Not a randomised controlled study design and no educational program that includes patient education aimed } \\
\text { at reducing diabetic foot ulcers. }\end{array}$ \\
\hline De Weerdt 1991 & $\begin{array}{l}\text { No educational program that included patient education aimed at reducing diabetic foot ulcers, and no relevant } \\
\text { outcomes reported. }\end{array}$ \\
\hline Donohoe 2000 & $\begin{array}{l}\text { No educational program targeted at patients that includes patient education aimed at reducing diabetic foot } \\
\text { ulcers. }\end{array}$ \\
\hline Glasgow 1992 & No relevant outcomes reported. \\
\hline Litzelman 1993 & $\begin{array}{l}\text { Foot care education is part of the comprehensive intervention on foot ulceration but not the main contrast with } \\
\text { the control. }\end{array}$ \\
\hline Litzelman 1997 & Not a randomised controlled study design. \\
\hline McCabe 1998 & Foot care education is not the main contrast with the control. \\
\hline McMurray 2002 & Foot care education is not the main contrast with the control. \\
\hline Pieber 1995 & Not a randomised controlled study design. \\
\hline Plank 2003 & $\begin{array}{l}\text { No educational program targeted at patients that includes patient education aimed at reducing diabetic foot } \\
\text { ulcers, and education not the main contrast with the control. }\end{array}$ \\
\hline Reichard 1993 & No educational program that includes patient education aimed at reducing diabetic foot ulcers. \\
\hline Schiel 2004 & Foot care education is not the main contrast with the control. \\
\hline Vinicor 1985 & $\begin{array}{l}\text { No educational program that includes patient education aimed at reducing diabetic foot ulcers, and no relevant } \\
\text { outcomes reported. }\end{array}$ \\
\hline Ward 1999 & Not a randomised controlled study design. \\
\hline Wooldridge 1996 & Not a randomised controlled study design. \\
\hline
\end{tabular}


DATA AND ANALYSES

Comparison 1. Effects of patient education in high risk patient samples

\begin{tabular}{lcccc} 
Outcome or subgroup title & $\begin{array}{c}\text { No. of } \\
\text { studies }\end{array}$ & $\begin{array}{c}\text { No. of } \\
\text { participants }\end{array}$ & Statistical method & Effect size \\
\hline $\begin{array}{l}\text { 1 Foot ulcer incidence (1 year } \\
\text { follow-up) }\end{array}$ & 1 & 354 & Risk Ratio (M-H, Fixed, 95\% CI) & $0.31[0.14,0.66]$ \\
$\begin{array}{l}2 \text { Foot ulcer incidence (1 year } \\
\text { follow-up) }\end{array}$ & 1 & 172 & Risk Ratio (M-H, Fixed, 95\% CI) & $1.00[0.70,1.44]$ \\
$\begin{array}{l}\text { Amputation Rate (1 year } \\
\text { follow-up) }\end{array}$ & 1 & 354 & Risk Ratio (M-H, Fixed, 95\% CI) & $0.33[0.15,0.76]$ \\
$\begin{array}{l}4 \text { Amputation rate (1 year } \\
\text { follow-up) }\end{array}$ & 1 & 172 & Risk Ratio (M-H, Fixed, 95\% CI) & $0.98[0.41,2.34]$ \\
\hline
\end{tabular}

\section{Analysis I.I. Comparison I Effects of patient education in high risk patient samples, Outcome I Foot ulcer incidence ( 1 year follow-up).}

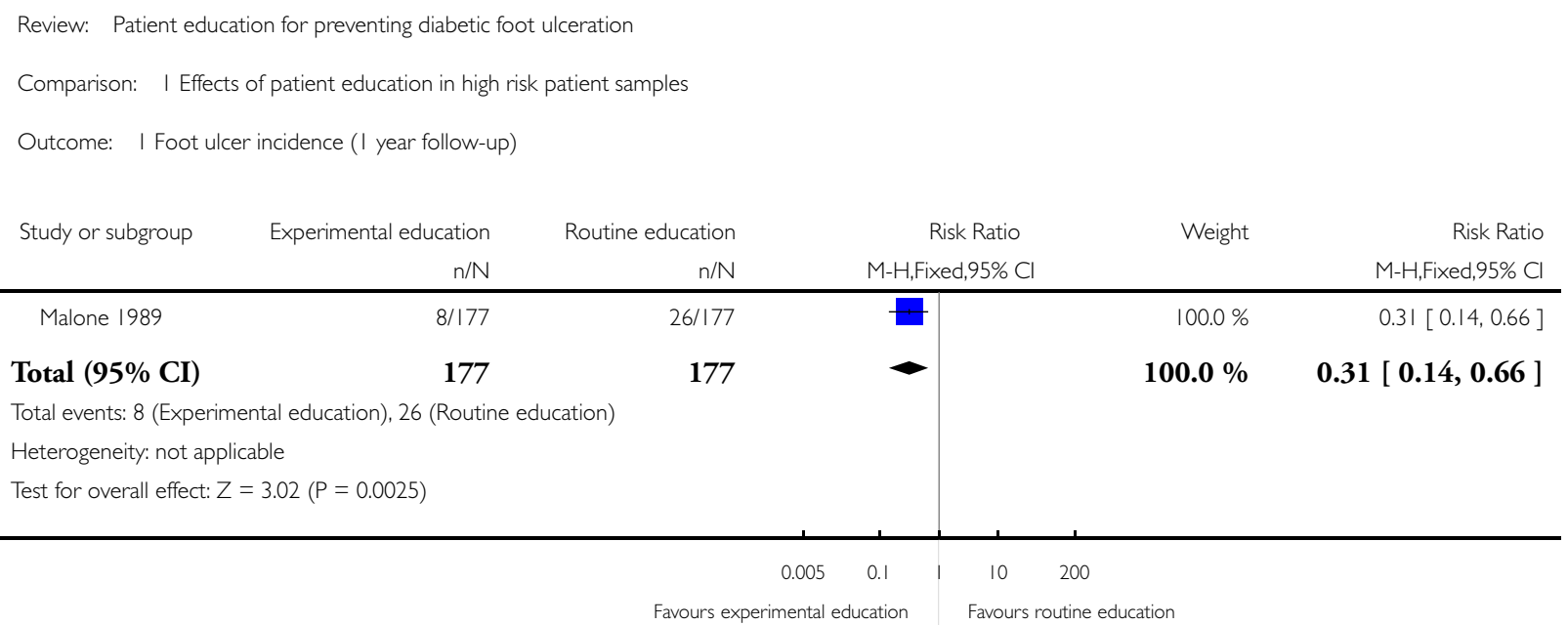


Analysis I.2. Comparison I Effects of patient education in high risk patient samples, Outcome 2 Foot ulcer incidence ( 1 year follow-up).

Review: Patient education for preventing diabetic foot ulceration

Comparison: I Effects of patient education in high risk patient samples

Outcome: 2 Foot ulcer incidence (I year follow-up)

\begin{tabular}{|c|c|c|c|c|c|}
\hline \multirow[t]{2}{*}{ Study or subgroup } & Experimental education & Written instructions only & Risk Ratio & Weight & Risk Ratio \\
\hline & $\mathrm{n} / \mathrm{N}$ & $\mathrm{n} / \mathrm{N}$ & M-H,Fixed,95\% Cl & & M-H,Fixed,95\% Cl \\
\hline Lincoln 2008 & $36 / 87$ & $35 / 85$ & & $100.0 \%$ & $1.00[0.70,1.44]$ \\
\hline Total (95\% CI) & 87 & 85 & - & $100.0 \%$ & $1.00[0.70,1.44]$ \\
\hline \multicolumn{6}{|c|}{ Total events: 36 (Experimental education), 35 (Written instructions only) } \\
\hline \multicolumn{6}{|c|}{ Heterogeneity: not applicable } \\
\hline \multicolumn{6}{|c|}{ Test for overall effect: $Z=0.03(P=0.98)$} \\
\hline
\end{tabular}

Analysis I.3. Comparison I Effects of patient education in high risk patient samples, Outcome 3 Amputation Rate (I year follow-up).

Review: Patient education for preventing diabetic foot ulceration

Comparison: I Effects of patient education in high risk patient samples

Outcome: 3 Amputation Rate ( year follow-up)

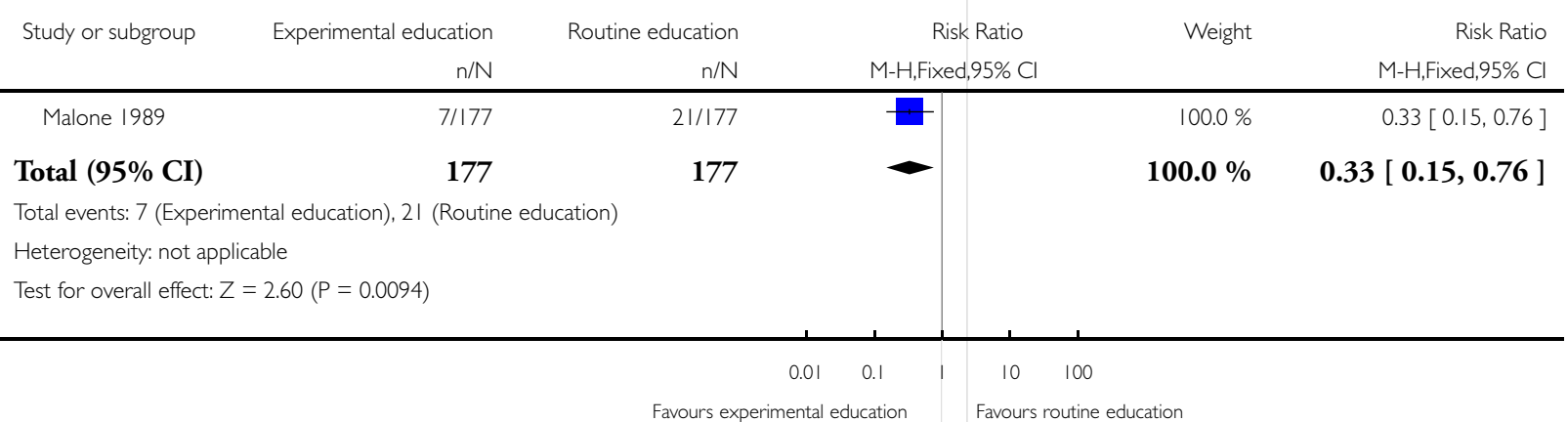




\section{Analysis I.4. Comparison I Effects of patient education in high risk patient samples, Outcome 4 Amputation rate (I year follow-up).}

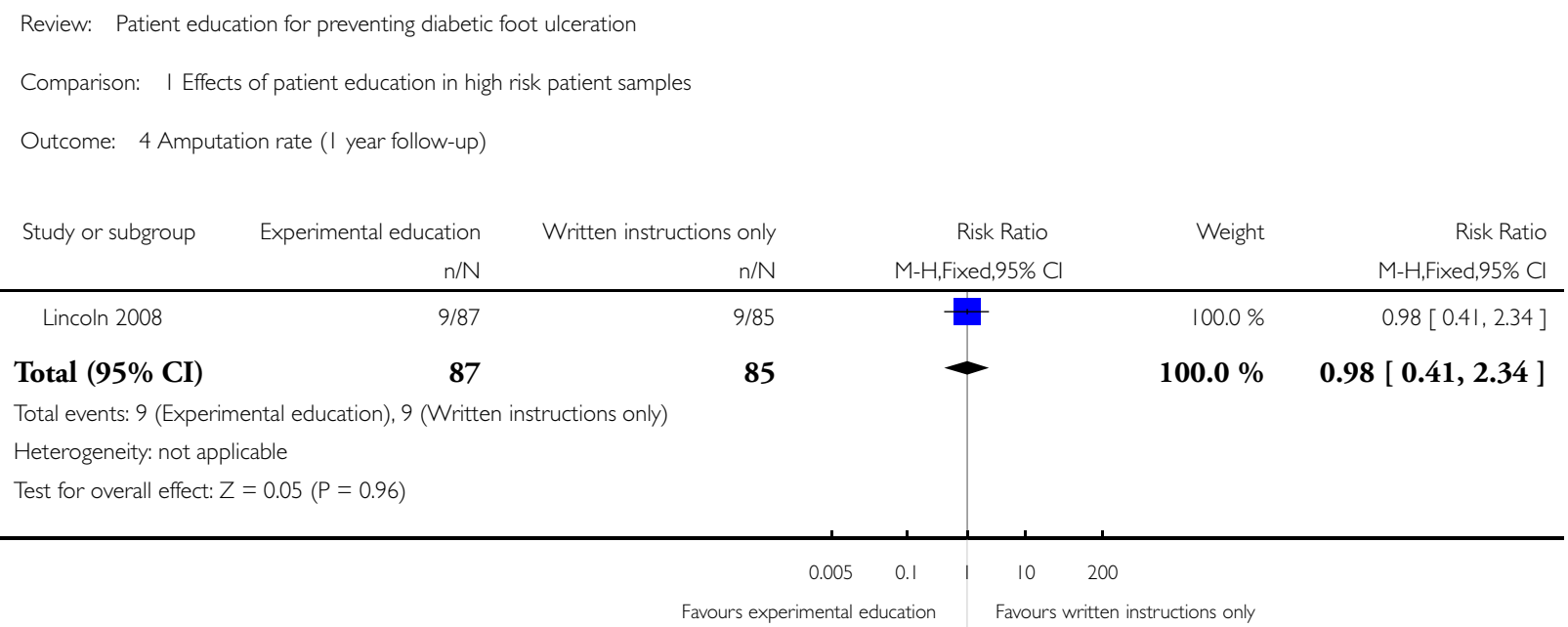

\section{A P P E N D I C E S}

\section{Appendix I. Search methods section for the first updated version - 2004}

For the update of this review we searched the Cochrane Wounds Group Specialised Register (September 2004) and The Cochrane Central Register of Controlled Trials (CENTRAL) (The Cochrane Library Issue 3, 2004), using the following strategy:

1. EDUCATION explode tree $1(\mathrm{MeSH})$

2. INSERVICE TRAINING explode tree $1(\mathrm{MeSH})$

3. TEACHING explode all trees $(\mathrm{MeSH})$

4. education*

5. pamphlet*

6. (leaflet* or booklet* or poster or posters)

7. (written near information)

8. (printed near information)

9. (oral near information)

10. (multidisciplinary near approach*)

11. (academic near detailing)

12. (training next program)

13. (algorithm* or (decision next tree*))

14. teaching

15. (\#1 or \#2 or \#3 or \#4 or \#5 or \#6 or \#7)

16. (\#8 or $\# 9$ or $\# 10$ or $\# 11$ or $\# 12$ or $\# 13$ or $\# 14$ )

17. $(\# 15$ or \#16)

18. FOOT ULCER explode all trees $(\mathrm{MeSH})$

19. DIABETIC FOOT explode all trees (MeSH)

20. (foot and ulcer*)

21. (diabetic near foot) 
22. (diabet* near ulcer*)

23. (diabet* near infection*)

24. (diabet* near wound*)

25. amputation*

26. (\#18 or \#19 or \#20 or \#21 or \#22 or \#23 or \#24 or \#25)

27. (\#17 and \#26)

We searched CINAHL (1982 to 2003), using the following search strategy:

1.(foot-ulcer* or leg-ulcer* or skin-ulcer*) in de

2.(diabetic-foot* or diabetic-neuropathies*) in de

3. (diabetic-angiopathies*) in de

4.(plantar or diabetic or heel (arterial near ulcer*)) in ti,ab

5.(foot or diabetic or ischaemic near ulcer*) in ti,ab

6. diabetic near foot in ti,ab

7.\#1 or \#2 or \#3 or \#4 or \#5 or \#6

8. patient-education* in de

9.(education or clinic* or therap*)in de

$10 . \# 8$ and $\# 9$

11. prevent* in de

12.\#10 and \#11 and \#7

13. (clinical-trials or single-blind-studies or double-blind-studies) in de

14. (control-group or placebos or meta-analysis) in de

15.(random* near clinical near trial*) or ((prospective near random*) in ti,ab)

16.((random near allocation) or random* or controlled-clinical-trial*) in ti,ab

17.\#13 or \#14 or \#15 or \#16

18.\#17 and \#12

The bibliographies of all retrieved and relevant publications identified by these strategies were searched for further studies. There was no restriction on language of the publications.

\section{Appendix 2. Ovid MEDLINE search strategy}

1 exp Education/

2 (patient adj 3 education).ti,ab.

3 (diabetes adj 3 education).ti,ab.

4 (patient adj3 information).ti,ab.

5 (education adj2 program\$).ti,ab.

6 (foot care or footcare).ti,ab.

7 (leaflet\$ or booklet\$ or pamphlet\$ or poster\$).ti,ab.

8 ((written or printed or oral) adj3 information).ti,ab.

9 academic detailing.ti,ab.

10 training program $\$ . t i, a b$.

11 (algorithm\$ or decision tree\$).ti,ab.

12 or/ $1-11$

13 exp Foot Ulcer/

14 exp Diabetic Foot/

15 (diabet\$ adj3 ulcer\$).ti,ab.

16 (diabet\$ adj3 (foot or feet)).ti,ab.

17 or/13-16

1812 and 17 


\section{Appendix 3. Ovid EMBASE search strategy}

1 exp Education/

2 (patient adj3 education).ti,ab.

3 (diabetes adj3 education).ti,ab.

4 (patient adj3 information).ti,ab.

5 (education adj2 program\$).ti,ab.

6 (foot care or footcare).ti,ab.

7 (leaflet\$ or booklet\$ or pamphlet\$ or poster\$).ti,ab.

8 ((written or printed or oral) adj3 information).ti,ab.

9 academic detailing.ti,ab.

10 training program $\$ . t i, a b$.

11 (algorithm\$ or decision tree\$).ti,ab.

12 or/ $1-11$

13 exp Foot Ulcer/

14 exp Diabetic Foot/

15 (diabet\$ adj3 ulcer\$).ti,ab.

16 (diabet\$ adj3 (foot or feet)).ti,ab.

17 or/13-16

1812 and 17

\section{Appendix 4. EBSCO CINAHL search strategy}

S21 S13 and S20

S20 S14 or S15 or S16 or S17 or S18 or S19

S19 TI diabet* N3 wound* or AB diabet* N3 wound*

S18 TI diabet* N3 infection* or AB diabet* N3 infection*

S17 TI ( diabet* N3 foot or diabet* N3 feet) or AB ( diabet* N3 foot or diabet* N3 feet )

S16 TI diabet* N3 ulcer* or AB diabet* N3 ulcer*

S15 (MH "Diabetic Foot")

S14 (MH "Foot Ulcer+")

$\mathrm{S} 13 \mathrm{~S} 1$ or $\mathrm{S} 2$ or $\mathrm{S} 3$ or $\mathrm{S} 4$ or $\mathrm{S} 5$ or $\mathrm{S} 6$ or $\mathrm{S} 7$ or $\mathrm{S} 8$ or $\mathrm{S} 9$ or $\mathrm{S} 10$ or $\mathrm{S} 11$ or $\mathrm{S} 12$

S12 TI ( algorithm* or decision tree*) or AB ( algorithm* or decision tree*)

$\mathrm{S} 11 \mathrm{TI}$ training program* or $\mathrm{AB}$ training program*

S10 TI academic detailing or $\mathrm{AB}$ academic detailing

S9 TI ( written N3 information or printed N3 information or oral N3 information ) or AB ( written N3 information or printed N3 information or oral N3 information )

S8 TI ( leaflet* or booklet* or pamphlet* or poster or posters ) or AB ( leaflet* or booklet* or pamphlet* or poster or posters )

S7 TI ( foot care or footcare ) or AB ( foot care or footcare )

S6 (MH "Foot Care")

S5 TI education* N3 program* or AB education* N3 program*

S4 TI diabetes $\mathrm{N} 3$ information or $\mathrm{AB}$ diabetes $\mathrm{N} 3$ information

S3 TI diabetes $\mathrm{N} 3$ education* or $\mathrm{AB}$ diabetes $\mathrm{N} 3$ education*

S2 TI patient N3 education* or AB patient N3 education*

S1 (MH "Patient Education+") 


\section{Appendix 5. Risk of Bias Table judgement criteria}

\section{Criteria for judgments for the sources of bias}

1. Was the allocation sequence randomly generated?

Yes, low risk of bias

The investigators describe a random component in the sequence generation process such as: Referring to a random number table; using a computer random number generator; coin tossing; shuffling cards or envelopes; throwing dice; drawing of lots.

\section{No, high risk of bias}

The investigators describe a non-random component in the sequence generation process. Usually, the description would involve some systematic, non-random approach, for example: sequence generated by odd or even date of birth; sequence generated by some rule based on date (or day) of admission; sequence generated by some rule based on hospital or clinic record number.

Unclear

Insufficient information about the sequence generation process to permit judgement of 'Yes' or 'No'

\section{Was the treatment allocation adequately concealed?}

\section{Yes, low risk of bias}

Participants and investigators enrolling participants could not foresee assignment because one of the following, or an equivalent method, was used to conceal allocation: Central allocation (including telephone, web-based and pharmacy-controlled randomization); Sequentially numbered drug containers of identical appearance; Sequentially numbered, opaque, sealed envelopes.

\section{No, high risk of bias}

Participants or investigators enrolling participants could possibly foresee assignments and thus introduce selection bias, such as allocation based on: Using an open random allocation schedule (e.g. a list of random numbers); Assignment envelopes were used without appropriate safeguards (e.g. if envelopes were unsealed or nonopaque or not sequentially numbered); Alternation or rotation; Date of birth; Case record number; Any other explicitly unconcealed procedure.

\section{Unclear}

Insufficient information to permit judgement of 'Yes' or 'No'. This is usually the case if the method of concealment is not described or not described in sufficient detail to allow a definite judgement for example if the use of assignment envelopes is described, but it remains unclear whether envelopes were sequentially numbered, opaque and sealed.

\section{Blinding was knowledge of the allocated interventions adequately prevented during the study?}

\section{Yes, low risk of bias}

Any one of the following:

- No blinding, but the review authors judge that the outcome and the outcome measurement are not likely to be influenced by lack of blinding;

- Blinding of participants and key study personnel ensured, and unlikely that the blinding could have been broken;

- Either participants or some key study personnel were not blinded, but outcome assessment was blinded and the non-blinding of others unlikely to introduce bias.

\section{No, high risk of bias}

Any one of the following:

- No blinding or incomplete blinding, and the outcome or outcome measurement is likely to be influenced by lack of blinding;

- Blinding of key study participants and personnel attempted, but likely that the blinding could have been broken;

- Either participants or some key study personnel were not blinded, and the non-blinding of others likely to introduce bias.

\section{Unclear}

Any one of the following:

- Insufficient information to permit judgement of 'Yes' or 'No';

- The study did not address this outcome.

\section{Were incomplete outcome data adequately addressed?}

\section{Yes, low risk of bias}

Any one of the following:

- No missing outcome data;

- Reasons for missing outcome data unlikely to be related to true outcome (for survival data, censoring unlikely to be introducing bias);

- Missing outcome data balanced in numbers across intervention groups, with similar reasons for missing data across groups; 
- For dichotomous outcome data, the proportion of missing outcomes compared with observed event risk not enough to have a clinically relevant impact on the intervention effect estimate;

- For continuous outcome data, plausible effect size (difference in means or standardized difference in means) among missing outcomes not enough to have a clinically relevant impact on observed effect size;

- Missing data have been imputed using appropriate methods.

\section{No, high risk of bias}

Any one of the following:

- Reason for missing outcome data likely to be related to true outcome, with either imbalance in numbers or reasons for missing data across intervention groups;

- For dichotomous outcome data, the proportion of missing outcomes compared with observed event risk enough to induce clinically relevant bias in intervention effect estimate;

- For continuous outcome data, plausible effect size (difference in means or standardized difference in means) among missing outcomes enough to induce clinically relevant bias in observed effect size;

- 'As-treated' analysis done with substantial departure of the intervention received from that assigned at randomization;

- Potentially inappropriate application of simple imputation.

\section{Unclear}

Any one of the following:

- Insufficient reporting of attrition/exclusions to permit judgement of 'Yes' or 'No' (e.g. number randomized not stated, no reasons for missing data provided);

- The study did not address this outcome.

\section{Are reports of the study free of suggestion of selective outcome reporting?}

\section{Yes, low risk of bias}

Any of the following:

- The study protocol is available and all of the study's pre-specified (primary and secondary) outcomes that are of interest in the review have been reported in the pre-specified way;

- The study protocol is not available but it is clear that the published reports include all expected outcomes, including those that were pre-specified (convincing text of this nature may be uncommon).

\section{No, high risk of bias}

Any one of the following:

- Not all of the study's pre-specified primary outcomes have been reported;

- One or more primary outcomes is reported using measurements, analysis methods or subsets of the data (e.g. subscales) that were not pre-specified;

- One or more reported primary outcomes were not pre-specified (unless clear justification for their reporting is provided, such as an unexpected adverse effect);

- One or more outcomes of interest in the review are reported incompletely so that they cannot be entered in a meta-analysis;

- The study report fails to include results for a key outcome that would be expected to have been reported for such a study.

Unclear

Insufficient information to permit judgement of 'Yes' or 'No'. It is likely that the majority of studies will fall into this category.

\section{Other sources of potential bias:}

\section{Yes, low risk of bias}

The study appears to be free of other sources of bias.

\section{No, high risk of bias}

There is at least one important risk of bias. For example, the study:

- Had a potential source of bias related to the specific study design used; or

- Had co-interventions which were not similar between the treatment and control groups.

- Had extreme baseline imbalance regarding demographic factors, duration and severity of complaints, for example size and duration of ulcer; or

- The compliance was unacceptable in all groups; or

- Had some other problem.

Unclear

Patient education for preventing diabetic foot ulceration (Review)

Copyright (C) 2010 The Cochrane Collaboration. Published by John Wiley \& Sons, Ltd. 
There may be a risk of bias, but there is either:

Insufficient information to assess whether an important risk of bias exists; or

Insufficient rationale or evidence that an identified problem will introduce bias.

\section{WHAT'S NEW}

Last assessed as up-to-date: 28 March 2010.

29 March 2010 New search has been performed

29 March 2010 New citation required and conclusions have changed
For this second update, new searches were carried out in December 2009. Four new studies were identified. Of these, three (Frank 2003; Borges 2004; Lincoln 2008) were included in the review and one (Schiel 2004) was excluded. The background section was updated and the review authors' conclusions amended.

Three adjustments were made to the review protocol: we have excluded studies in which the intervention consisted of multiple combined strategies for the prevention of diabetic foot ulceration, where patient education was not the main comparator with the control intervention (Litzelman 1993) this study is now included in a Cochrane review of complex interventions (Dorresteijn 2010). In addition we have redefined the previously used primary outcome 'infection' into the secondary outcome 'fungal infection'. Thirdly, we have completed a risk of bias assessment based on guidance from the Cochrane Handbook.

\section{H I S T O R Y}

Protocol first published: Issue 1, 1999

Review first published: Issue 4, 2001

\begin{tabular}{|c|c|c|}
\hline 25 March 2008 & Amended & Converted to new review format. \\
\hline 10 September 2004 & New search has been performed & $\begin{array}{l}\text { This review was originally published in the Cochrane } \\
\text { Library, Issue 4, } 2001 . \\
\text { For this first update, new searches were carried out in } \\
\text { September 2004. Six new studies were identified. Of } \\
\text { these, one study (Corbett 2003) was included in the } \\
\text { review and five studies (Dargis 1999, Davidson, 2000, } \\
\text { Donohoe, 2000, McMurray, 2002, Plank 2003) were } \\
\text { excluded. } \\
\text { The reviewers' conclusions remain unchanged. }\end{array}$ \\
\hline 20 August 2001 & New citation required and conclusions have changed & Substantive amendment \\
\hline
\end{tabular}




\section{CONTRIBUTIONS OFAUTHORS}

GD Valk conceived and coordinated the review and is guarantor for the review.

GD Valk and WJJ Assendelft designed the review and wrote the protocol.

GD Valk, DMW Kriegsman and WJJ Assendelft wrote the original review.

GD Valk, DMW Kriegsman and JAN Dorresteijn extracted, analysed and interpreted data.

JAN Dorresteijn completed the first draft of the revised and updated review text.

GD Valk, DMW Kriegsman and WJJ Assendelft contributed to and edited the updated review text.

\section{Contributions of editorial base:}

Nicky Cullum: edited the review, advised on methodology, interpretation and review content. Approved the final review and review update prior to submission.

Sally Bell-Syer: coordinated the editorial process. Advised on methodology, interpretation and content. Edited and copy edited the updated review.

Ruth Foxlee: designed the search strategy, ran the searches and edited the search methods section for the update.

\section{DECLARATIONS OF INTEREST}

None known.

\section{SOURCES OF SUPPORT}

\section{Internal sources}

- Dutch Cochrane Centre, Netherlands.

- Leiden University Medical Center, Department of Public Health and Primary Care, Netherlands.

- University Medical Center Utrecht, Department of Internal Medicine, Netherlands.

\section{External sources}

- No sources of support supplied

\section{DifFERENCES BETWEEN PROTOCOL AND REVIEW}

In this updated review, we have excluded studies in which the intervention consisted of multiple combined strategies for the prevention of diabetic foot ulceration, where patient education was not the main comparator with the control intervention (Litzelman 1993). We have developed and published a further Cochrane review which provides a more comprehensive overview of the effects of such integrated prevention strategies (complex interventions)(Dorresteijn 2010). In addition, we have redefined the previously used primary outcome 'infection' into the secondary outcome 'fungal infection'. Furthermore, while the Amsterdam-Maastricht consensus list was used to score risk of bias in previous versions of this review (van Tulder 1997), we have adopted the Cochrane Collaboration's recommended tool for assessing risk of bias in this update (Higgins 2008). 


\section{N D EX TERMS}

\section{Medical Subject Headings (MeSH)}

*Patient Education as Topic; Diabetic Foot [* prevention \& control]; Randomized Controlled Trials as Topic

\section{MeSH check words}

Humans 